Policy Research Working Paper 1856

Surviving Success

\section{Policy Reform and the Future of Industrial Pollution in China}

Susmita Dasgupta

Hua Wang

David Wheeler
Lax regulation of industrial

pollution is causing thousands

of premature deaths and serious health problems in China. Pollution abatement would cost fittle; inaction? amounts to valuing a chinese worker's life below US\$500, a tragically low figure by any standard.

The World Bank

Development Research Group

November 1997 
Policy Research Working Paper 1856

\section{Summary findings}

China's recent industrial growth, a remarkable success story, has been clouded by hundreds of thousands of premature deaths and incidents of serious respiratory illness caused by exposure to industrial air pollution. Seriously contaminated by industrial discharges, many of China's waterways are largely unfit for direct human use.

This damage could be substantially reduced at modest cost. Industrial reform combined with stricter environmental regulation has reduced organic water pollution in many areas and has curbed the growth of air pollution. But much higher levels of emissions controls (of particulates and sulfur dioxide) are warranted in China's polluted cities.

For the cost-benefit analysis that led to this conclusion, the authors developed three scenarios projecting pollution damage under varying assumptions about future policies. Their findings:

Even if regulation is not tightened further, continued economic reform should have a powerful effect on pollution intensity. Organic water pollution will stabilize in many areas and actually decline in some. Air pollution will continue growing in most areas but at a much slower pace than industrial output.

The cost of inaction would be high: Most of China's waterways will remain heavily polluted, and many thousands of people will die or suffer serious respiratory damage.

Continuing current trends in tightened regulation for water pollution will lead to sharp improvements; adopting an economically feasible policy of much stricter regulation will restore the health of many waterways.

The stakes are even higher for air pollution because regulatory enforcement has weakened in many areas in the past five years. Reversing that trend will save many lives at extremely modest cost. China's National Environmental Protection Agency (NEPA) has recommended a tenfold increase in the air pollution levy; adopting NEPA's very conservative recommendation would produce a major turnaround in most cities. For representative Chinese cities, a fiftyfold increase in the levy is probably warranted economically.

To be cost-effective, heavy sources of particulate and sulfur dioxide emissions should be targeted for abatement. Reducing emissions from large private plants is so cheap that only significant abatement makes sense - at least 70 percent abatement of sulfur dioxide particulates and even greater abatement of particulates in large urban industrial facilities.

This paper - a product of the Development Research Group - is part of a larger effort in the group to identify appropriate policies for environmental regulation in developing countries. The study was funded by the Bank's Research Support Budget under the research project "The Economics of Industrial Pollution Control in Developing Countries" (RPO 680-20). Copies of this paper are available free from the World Bank, $1818 \mathrm{H}$ Street NW, Washington, DC 20433. Please contact Susmita Dasgupta, room N10-035, telephone 202-473-2679, fax 202-522-3230, Internet address sdasgupta@worldbank.org. November 1997. (52 pages)

The Policy Research Working Paper Series disseminates the findings of work in progress to encourage the exchange of ideas about development issues. An objective of the series is to get the findings out quickly, even if the presentations are less than fully polished. The papers carry the names of the authors and should be cited accordingly. The findings, interpretations, and conclusions expressed in this paper are entirely those of the authors. They do not necessarily represent the view of the World Bank, its Executive Directors, or the countries they represent. 


\title{
Surviving Success: \\ Policy Reform and the Future of Industrial Pollution in China
}

by

\author{
Susmita Dasgupta* \\ Hua Wang \\ David Wheeler
}

Correspondence should be addressed to:

Susmita Dasgupta, N10-035, World Bank, 1818 H St., NW, Washington, DC 20433

\footnotetext{
* The authors are respectively Economist, Consultant and Principal Economist in the Environment, Infrastructure and Agriculture Division, Policy Research Department, World Bank. Our thanks to Richard Newfarmer, Todd Johnson, Gordon Hughes, Kseniya Lvovsky, Feng Liu and Muthukumara Mani for many useful comments and suggestions. This paper has been produced in a collaborative program with China's National Environmental Protection Agency and the World Bank's Country Department EA2.
} 



\section{Introduction}

China's industrial growth has been extremely rapid during the period of economic reform. In the 1990s, the output of China's 10 million industrial enterprises has increased by more than $15 \%$ annually. Industry is also China's largest productive sector, accounting for $47 \%$ of its gross domestic product and employing $17 \%$ of the country's total labor force. As a source of rapidly expanding income, Chinese industry has provided one of strongest forces lifting many millions of people from poverty.

Unfortunately, serious environmental damage has accompanied this rapid growth. Many of China's waterways are close to biological death from excessive discharge of organic pollutants. In many urban areas, atmospheric concentrations of pollutants such as suspended particulates and sulfur dioxide routinely exceed World Health Organization safety standards by very large margins. As a result, hundreds of thousands of people are dying or becoming seriously ill from pollution-related respiratory disease each year.

There can be no doubt that Chinese industry is a primary source of this problem. China's National Environmental Protection Agency (NEPA) estimates that industrial pollution accounts for over $70 \%$ of the national total, including $70 \%$ for waste water, including organic water pollution (COD, or chemical oxygen demand); $72 \%$ for sulfur dioxide (SO2) emissions; 75\% for flue dust (a major component of suspended particulates) and $87 \%$ for solid wastes. Many polluting industries are located in densely-populated metropolitan areas, where emissions exposure causes particularly serious damage to human health and economic activity.

China's pollution control agencies are aware of these problems, and have responded with stricter enforcement of regulatory standards for water pollutants. As a result, many industrial enterprises have reduced emissions through adoption of end-of-pipe equipment, process change and materials recycling. Since 1987, provinces which have tightened enforcement have witnessed a substantial decline in the water pollution intensity, or pollution per unit of output, of factories which are under regulatory supervision. ${ }^{1}$ Emissions intensity for some water pollutants has declined so rapidly that total emissions have fallen despite rapid industrial growth.

Unfortunately, the same cannot be said for industrial air pollution. The evidence shows that some regulatory incentives for air pollution control have actually weakened since 1987. Industrial discharges continue at very high levels, seriously contaminating the atmosphere of many cities. Figure 1 shows the strong relationship between emissions of $\mathrm{SO} 2$ and atmospheric concentrations in fifty-three Chinese cities during the period 19911993.

\footnotetext{
${ }^{1}$ It is important to note that this does not include many Township and Village Industrial Enterprises (TVIE's), which are often highly-polluting and account for a major share of China's industrial production.
} 
As we will show in this paper, market reforms have been another important source of change in environmental performance. The reforms have shifted production away from state-owned-enterprises and toward larger plants. With these changes have come substantial increases in productive efficiency and decreases in the cost of abating pollution, both important sources of declining pollution intensity. These two factors may have had as great an impact on industrial pollution as changes in direct regulation.

Sulfur Dioxide: Emissions and Atmospheric Concentration in Chinese Cities, 1991-1993

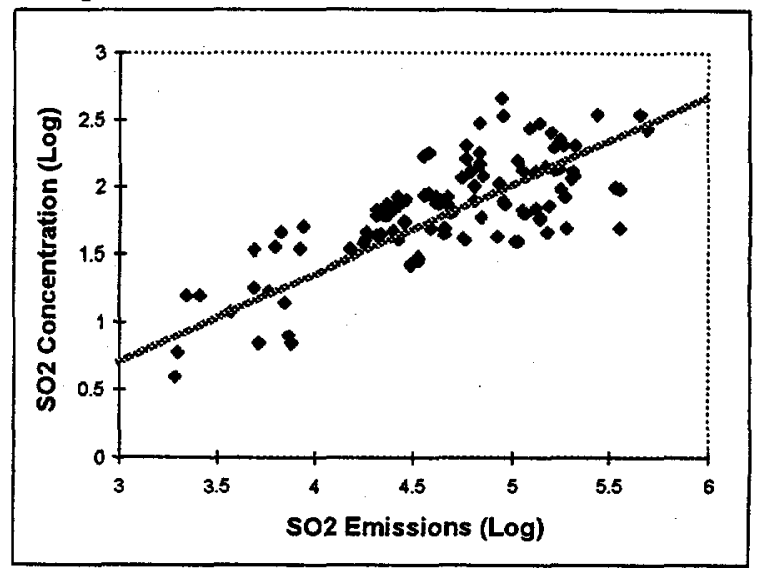

Figure 1: SO2 Emissions and Air Pollution in Chinese Cities

Although the general trend is positive, there remain great regional disparities in industry's environmental performance. In provinces with stricter regulation and a strong commitment to economic reform, many industrial facilities have already shown the way to a cleaner future. However, the legacy of the past remains strikingly apparent in thousands of highly-polluting plants. With industry expected to maintain rapid growth during the next 20 years, a steep decline in pollution intensity will be necessary just to keep emissions constant.

The consequences of current pollution are tragically apparent in public health statistics for polluted areas. As we will show, the best available evidence suggests that approximately 4,000 people suffer premature death from pollution-related respiratory illness each year in Chongqing; 4,000 in Beijing; and 1,000 in both Shanghai and Shenyang. ${ }^{2}$ If current trends persist, we project large cumulative losses in human life through 2020. Figure 2 illustrates the grim stakes: Beijing could lose nearly 80,000 people, Chongqing 70,000 and other major cities could suffer losses in the tens of thousands.

${ }^{2}$ These estimates are based on the dose-response relation established for atmospheric SO2 in Beijing and Shenyang by Xu, et. al. (1994). This relation is combined with monitoring data on SO2 concentrations to produce estimated individual probabilities of premature mortality by city. City-specific probabilities are multiplied by current population estimates to produce estimated annual deaths. 
In light of other pressing needs, how strongly should China respond to this challenge? Environmental improvements are desirable, but pollution abatement uses valuable economic resources and there may be other, less costly, health interventions which will save lives. Nevertheless, after a careful assessment of the benefits and costs, this paper will argue that stricter regulation of air emissions in heavily-polluted areas is a very cost-effective option for public health improvement. We will also highlight the beneficial effect of recent economic reforms on public health, through their impact on industrial pollution intensity. Other compelling arguments for continued modernization of China's economy are bolstered by its clear environmental benefits.

The rest of the paper is organized as follows. In Section 2, we introduce five provinces which will be used to illustrate the scope of China's industrial pollution problems and the options for policy reform. Section 3 draws on several recent research papers to describe the impact of China's economic reforms and environmental regulations on industrial pollution since 1987. In Sections 4 and 5, we explore the implications with several scenarios for policy reform, pollution reduction, and associated health benefits during the next two decades. Section 6 uses our results for a detailed benefit/cost analysis of stricter air pollution control; Section 7 considers more general policy implications, and Section 8 concludes the paper.

\section{Industrial Pollution in China's Regions}

China is continental in scale, with great regional variation in social, economic and environmental conditions. To illustrate the implications for environmental policy, we highlight the experience of five diverse provinces which have serious industrial pollution problems: Liaoning, Beijing, Shanghai, Guangdong, and Sichuan (Fig. 3). ${ }^{3}$ The first four provinces are scattered from north to south in China's eastern coastal region. Beijing's industry has a diversity which reflects its status as the nation's political capital. In contrast, Liaoning is a traditional center for Chinese heavy industry; many of its factories have old, highly polluting processes which depend on coal-based energy. Shanghai's

\footnotetext{
${ }^{3}$ In this paper, the term "province" refers to provinces, autonomous regions and municipalities which are directly affiliated with the central government.
} 
industrial base is extremely diverse, but its sheer scale assures. a large potential pollution problem. On the other hand, Shanghai has joined Guangdong as a center of China's economic modernization, with attendant benefits for pollution reduction. Guangdong has its own particular interest for the analysis, because its industrial development has

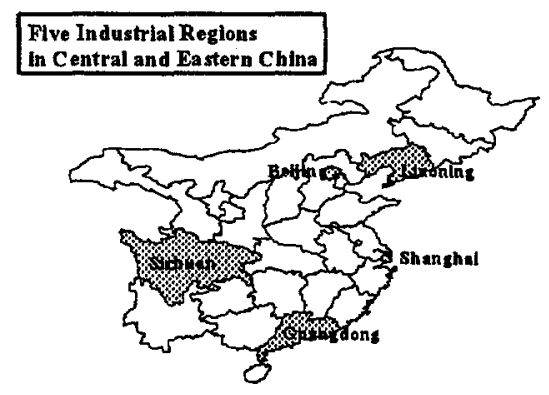

featured the growth of light

manufacturing which operates at smaller scale than China's average. Finally, Sichuan is located in the Red Basin, in south-central China. It is considerably poorer than the other four provinces, and its industry is highly pollution-intensive.

Figure 4 displays income (consumption) per capita in 1988 and 1993: Shanghai had the highest level initially, and has bounded ahead in the period of economic reform. Guangdong and Liaoning grew more rapidly than Beijing during the five-year period, arriving at near-parity in 1993. From a much lower base, Sichuan has grown at approximately the same rate as Guangdong and Liaoning. It remains the poorest of the five provinces by a considerable margin.

It might seem logical for China's richest provinces to be the most highly polluted, but

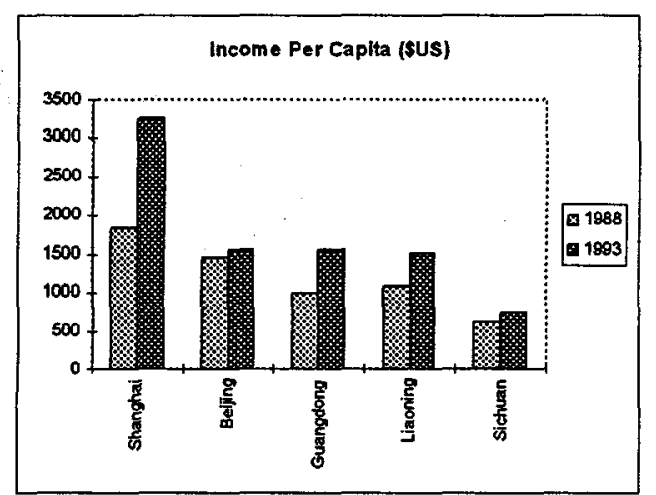

Figure 4: Income Per Capita, 1988 and 1993

Figure 5 strongly suggests the converse: There is an inverse relationship between industrial pollution and economic development, most strongly in the case of air pollution. Sichuan is the clear leader, with both sulfur dioxide (SO2) and total suspended particulate (TSP) emissions exceeding 1,000,000 tons/year in both 1998 and 1993. Although it has substantially reduced organic water pollution (chemical oxygen demand - COD) in recent years, Chongqing remains, with Liaoning, the most highly polluted province in this category as well. Despite its huge industrial base, Shanghai has far lower pollution loads, while Beijing and Guangdong are also modest emitters by comparison. ${ }^{4}$

4 Analysis of air emissions data for all twenty-nine provinces reveals the same pattern: The poorest provinces have significantly higher total emissions. 
Atmospheric pollution levels reflect these differences in emissions, as suggested by Figure

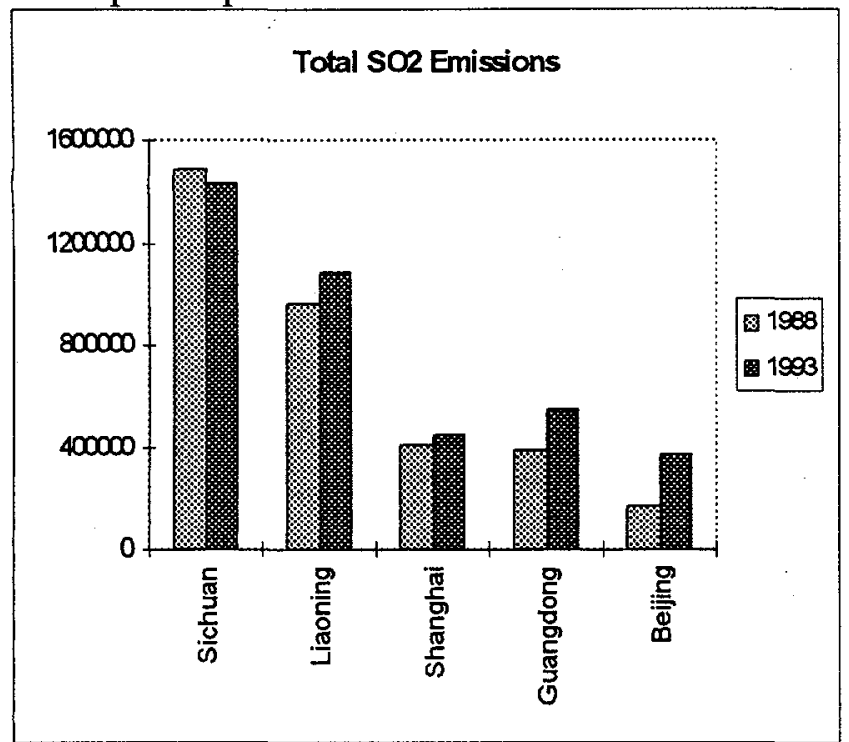

1. Figure 6 presents $\mathrm{SO} 2$ concentration levels for Beijing, Shanghai, and the major cities of the other three provinces: Shenyang (Liaoning), Guangzhou (Guangdong) and Chongqing (Sichuan). Again, the highest level by far is observed in Chongqing. The result is a very large difference in the risk of death or serious damage from respiratory disease, with consequences that have been illustrated in Figure 2.
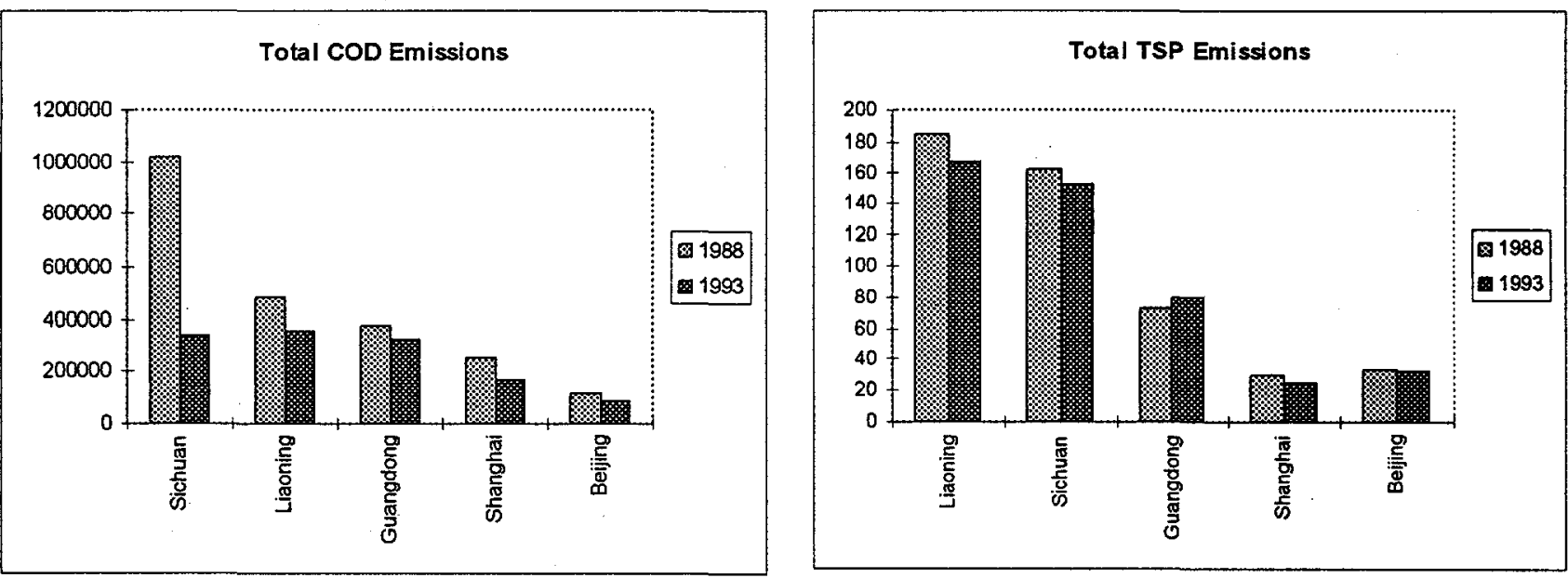

Figure 5: Air and Water Pollution Loads, 1988 and 1993 


\section{Economic Reform, Regulation and Pollution Reduction Since 1987}

\subsection{The Basic Economics of Industrial Pollution Control}

Figures 2 and 5 reveal great variation in industrial emissions and pollutionrelated mortality across provinces. As Figure 7 suggests, however, the differences in emissions are not primarily due to differences in the scale of industrial activity. Rather, they reflect differences in pollution intensity, or pollution per unit of output: Industry is 'dirtiest' in Sichuan, 'cleanest' in Shanghai; Liaoning and Guangdong have more

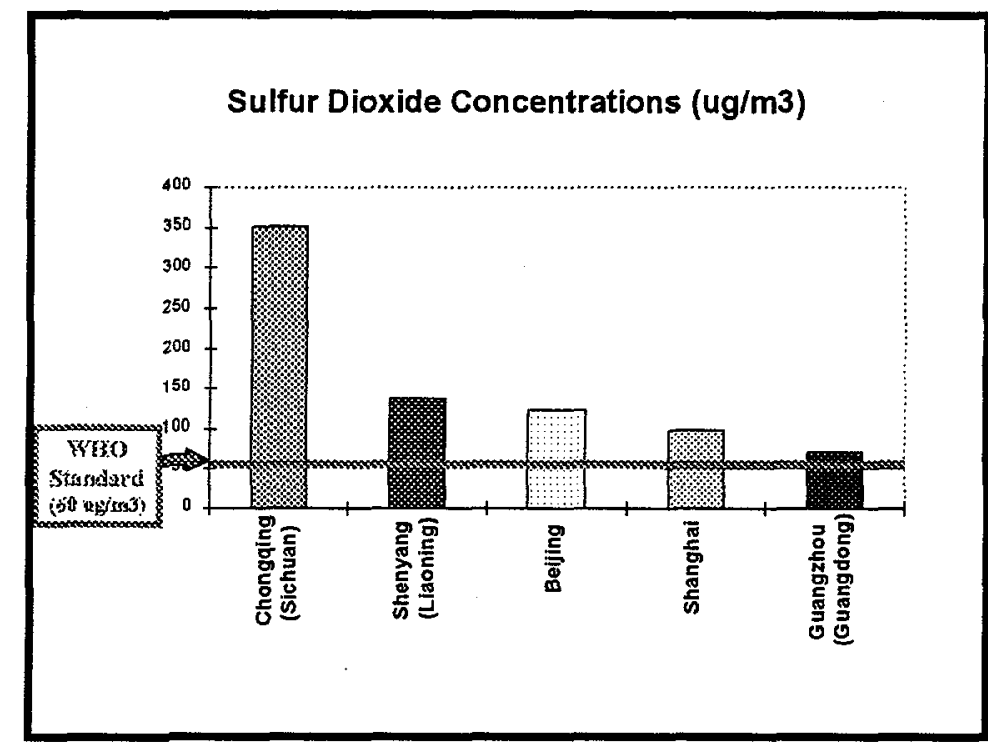

Figure 6: SO2 Concentration Levels, 1992

pollution-intensive industry than Beijing. Figure 7 also reveals some remarkable changes in a very short period of time: Pollution intensity has fallen sharply since 1988, with particularly strong and consistent reductions in Guangdong and Sichuan.
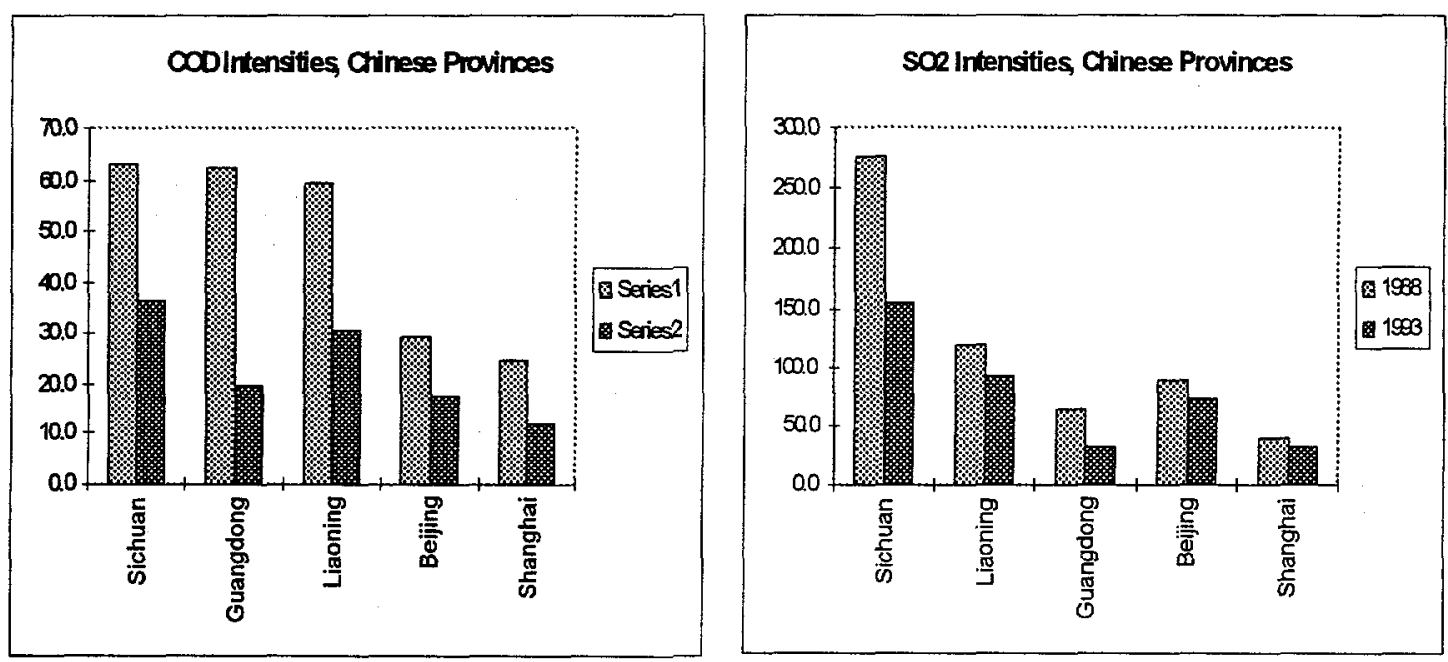

Figure 7a: Provincial Differences in Industrial Pollution Intensity 


\subsection{Key Factors for Improved Environmental Performance}

What can account for such variations? Our recent research has shown that several factors play important roles in factory managers' abatement decisions: Regulation; plant and industry characteristics; and pressure applied by neighboring communities (Hettige, Huq, Pargal and Wheeler, 1996; Pargal and Wheeler, 1996). By assessing penalties for non-compliance, regulators raise the 'price of polluting' and provide economic incentives for lowering emissions. However, the degree of response to these incentives varies widely by

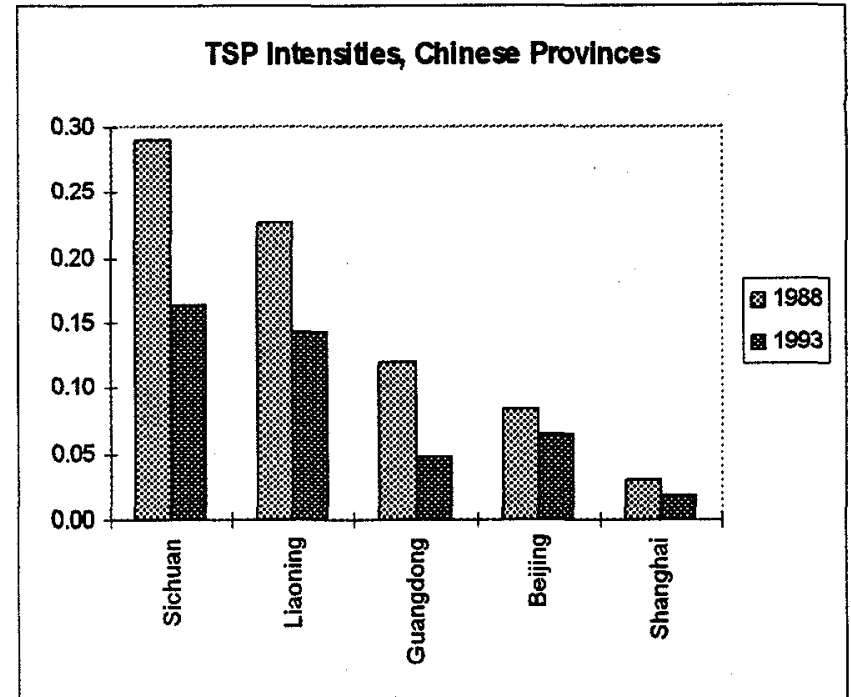

Figure 7b: Provincial Differences in Industrial Pollution Intensity industry sector, type of ownership, and scale of operations. There is also strong evidence that local communities exert independent influence on abatement decisions through various forms of 'informal' pressure on plant managers (e.g. political leaders, community leaders, the media). Richer, better-educated communities seem to operate quite effectively through such informal means.

\section{Regulation}

In China, national, provincial and local pollution control agencies can affect factory-level emissions by enforcing the existing emissions standards, pollution levies and other regulatory instruments. Penalties for non-compliance raise the 'price of polluting' for factories and lead to increased pollution control activity. However, our recent research in China and other Asian countries has shown that the impact of regulation is mediated by the consistency and strictness of enforcement (Hartman, Huq and Wheeler, 1997; Wang and Wheeler, 1996). Pollution abatement incurs costs, so the interest of plant managers in emissions control is highly dependent on the likelihood that non-compliance will be detected by the authorities. This, in turn, depends on the monitoring and inspection resources made available to local regulators. Even if non-compliance is detected, the degree of management responsiveness depends largely on the size of the legally-specified penalties and the proportion which is actually collected by the authorities.

NEPA's own reports suggest that consistency and strictness of enforcement have varied greatly across China's provinces (Dasgupta, Huq and Wheeler, 1997). Figure 8 provides evidence on two comparable measures of regulatory strictness: Actual collections of pollution levy assessments (or 'effective levies') per unit of excess (above-standard) 
discharge of wastewater and per unit of discharge for air pollutants. Comparison with Figure 7 reveals a roughly inverse relationship between ranking on pollution intensity and ranking on effective levies. Beijing has the highest effective levies and is among the lowest in pollution intensity; the converse is true for Sichuan. In both cases, Guangdong and Liaoning are intermediate. Notably, however, Shanghai does not conform to the general pattern: Its effective air pollution levy seems entirely out of line, both with its effective water pollution levy and its status as the area with lowest pollution intensity.
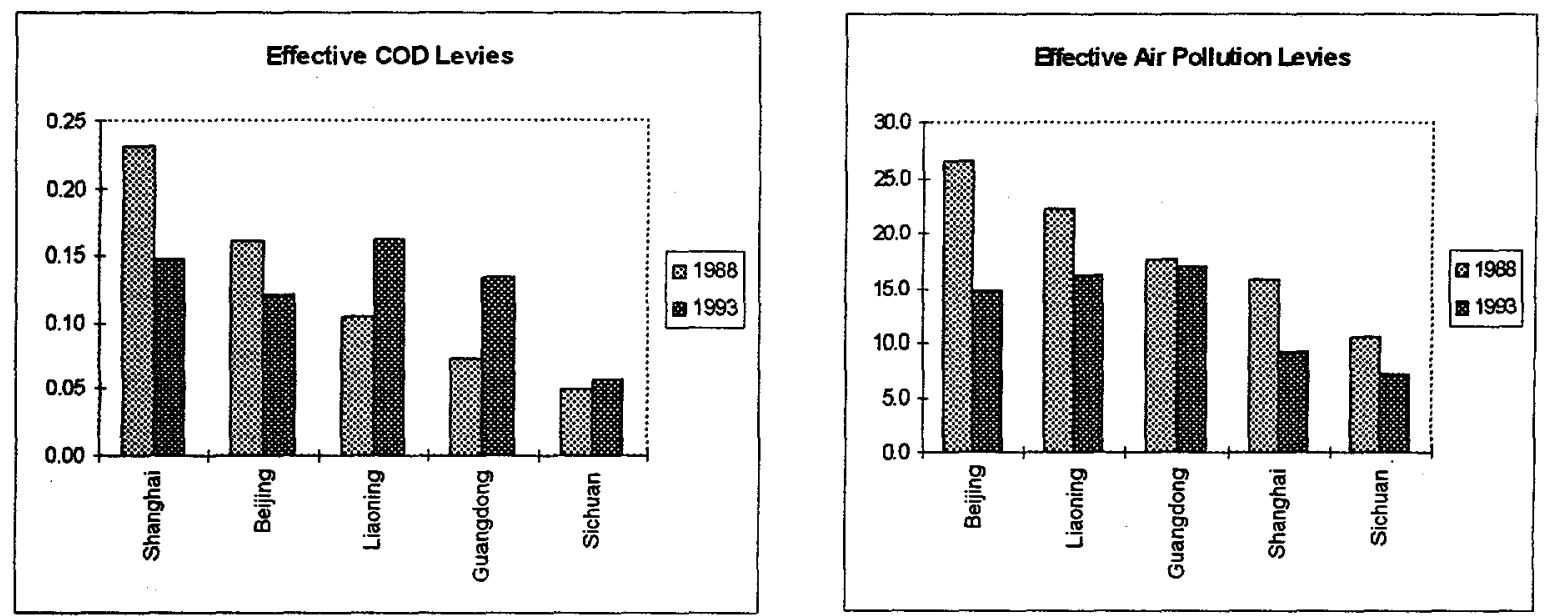

Figure 8: Provincial Differences in Effective

Regulation

Our research has shown that these variations in effective levies have had significant effects on the pollution intensity of production across China's provinces. Each $1 \%$ increase in the effective water pollution levy (from increased levels of legally-defined penalties or tightened enforcement) leads to an approximately . $8 \%$ decrease in COD pollution intensity (COD per unit of output). Each $1 \%$ increase in the effective air discharge levy leads to decreases of approximately $.3 \%$ in $\mathrm{SO} 2$ intensity. For the two components of suspended particulates, industrial smoke and dust, reductions in emissions intensity are $.8 \%$ and $.4 \%$, respectively, when the effective air levy is raised by $1 \%$. It is clear that regulation makes a significant difference, and that China's provincial regulators have pursued quite different regulatory policies. ${ }^{5}$

Why do regulators behave so differently? Our research findings are summarized in Figure 9. They suggest that two broad sets of factors

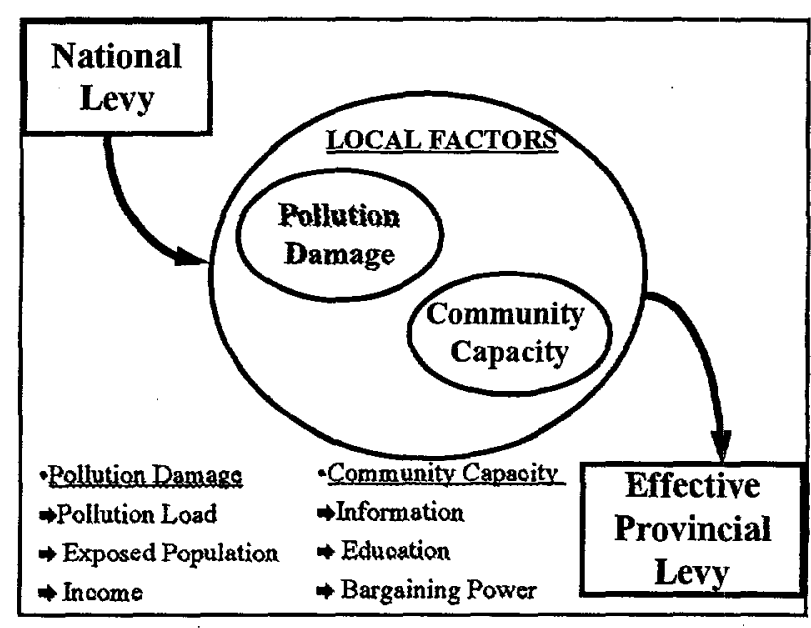

Figure 9: Sources of Variation in Provincial Regulation

\footnotetext{
${ }^{5}$ The econometric results are summarized in the Appendix.
} 
influence regulatory enforcement policy (Afsah, Laplante and Wheeler, 1996). Local regulators are apparently responsive to economic factors which influence total damage assessment. These include the local pollution load, the size of the exposed population, and local income per capita. However, effective levies are also affected by differential community capacity to enforce, which depends on average education, available information and the power to bargain with local industry.

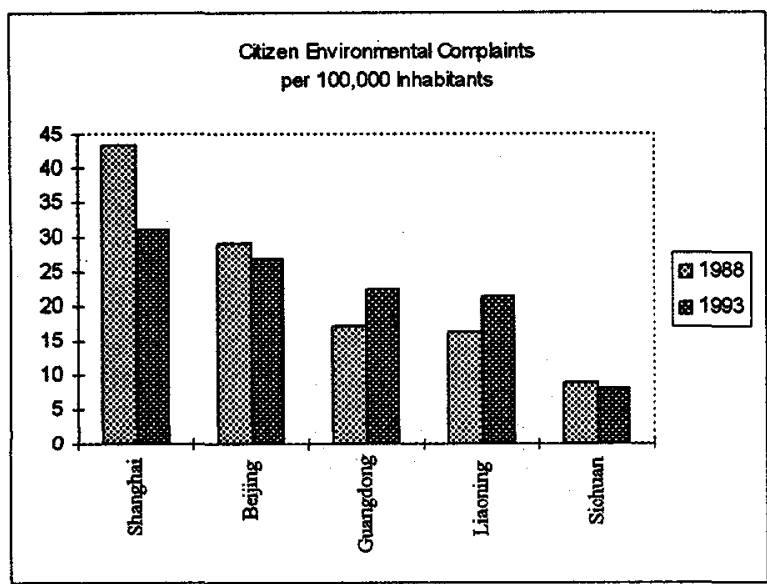

Figure 10: Provincial Differences in Citizen Complaints
Our results also suggest that regulators respond to citizen complaints, whose incidence varies widely across provinces (Dasgupta and Wheeler, 1996). Complaints per capita are most strongly related to average education levels: Areas with high illiteracy are notably 'silent,' because uneducated citizens are less likely to be aware of environmental problems and less willing to confront the authorities. Provincial TSP pollution also has significant effects on the incidence of complaints. Figure 10 illustrates the implications of the educational and income

effects for our five provinces: The incidence of complaints is positively associated with effective air and water pollution levies, and negatively associated with actual pollution intensity. Our evidence suggests that this kind of citizen feedback is a powerful independent force for environmental improvement.

\section{Plant and Industry Characteristics}

Our research has identified three variables in this category which are significant contributors to pollution intensity in a particular region. The first, not surprisingly, is the sectoral composition of industry. Some industrial processes generate large volumes of harmful pollutants; others do not. Some sectors also face substantially higher abatement costs, increasing the resistance to pollution control in cost-sensitive enterprises.

Scale of operation is also an important determinant of pollution intensity. In part, this is because end-of-pipe pollution abatement has very significant scale economies. Large plants have lower unit costs of abatement, and respond more readily to regulatory incentives. They also tend to be more technically efficient, since their size permits spreading overhead costs for skilled personnel across many units of production.

Our research also suggests that state-owned enterprises (SOE's) are substantially more pollution-intensive than other plants in China. The basic cause is apparently lower operating efficiency, which affects both abatement costs and the generation of waste residuals in production. Recent research in Asian mixed economies has suggested that SOE's' insulation from regulation is another contributing factor (Pargal and Wheeler, 
1996; Hartman, Huq and Wheeler, 1997). However, our analysis of enforcement practices in China finds the converse to be true there: SOE's experience more, not less rigorous enforcement (Dasgupta, Huq and Wheeler, 1997). Their greater pollution intensity in China therefore seems attributable to efficiency effects alone.

\section{Comparative Significance of Pollution Intensity Factors}

Figures 11 and 12 summarize the results of our econometric analysis of provincial differences in water and air pollution intensity. The intensity factors displayed in the Figures are based on beta coefficients, which measure the direction and relative importance of explanatory variables in a multivariate relationship. For both water (COD) and air (SO2) pollution intensity, the share of production in

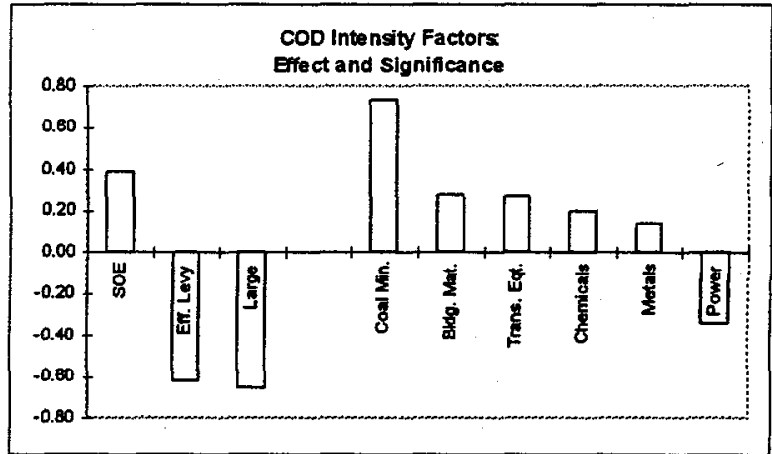

Figure 11: COD Intensity Factors large plants is the most significant factor in reducing intensity. ${ }^{6}$ Its beta-coefficient measure (approximately .60 ) is essentially the same in the two cases. The share of production in state-owned plants has large weight as a contributor to pollution intensity, with a beta measure of approximately .40 in both cases. The economic incentive for pollution abatement provided by the pollution levy is also important, although apparently more so for COD pollution. The beta coefficient for the effective water levy is approximately .60, while it is in the range $(.20-.40)$ for the effective levy on air pollutant discharges.

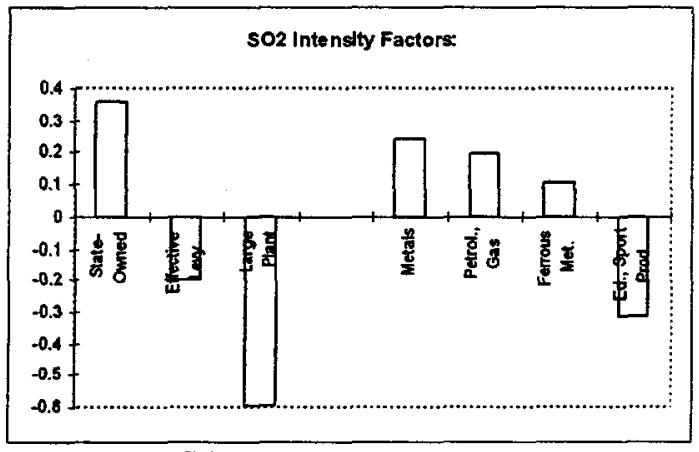

Figure 12: SO2 Intensity Factors
Among sectors, the major contributors to higher intensity vary by pollutant. ${ }^{7}$ For COD pollution, the significant 'dirty' sectors are Coal Mining, Building Materials, Transport Equipment, Chemicals and Metals. In the case of air pollutants, Metals, Petroleum/Gas and Ferrous Metals are exceptionally 'dirty' for SO2; Furniture, Metals, Electrical Equipment, Textiles, Paper, and Ferrous Metals for TSP.

${ }^{6}$ The results for smoke and dust intensity, the two components of TSP intensity, are similar to those for $\mathrm{SO} 2$.

7 These sectors are identified by multivariate analysis, in which exceptionally 'clean' or 'dirty' sectors are those which depart significantly from average pollution intensities after the effects of the levy, scale and ownership are accounted for. 


\subsection{The Reform Experience Since 1987}

China's economic reforms during the past decade have focused on increasing the role of price signals in the economy, reducing constraints on enterprise expansion (and contraction), reducing the role of SOE's, and reducing trade protection. The results have included extremely rapid industrial growth and major changes in economic structure. The reforms have also had a major impact on industrial pollution, because they have affected the sectoral composition of output, the size distribution of Chinese factories, their ownership, and their sensitivity to economic incentives provided by the pollution levies.

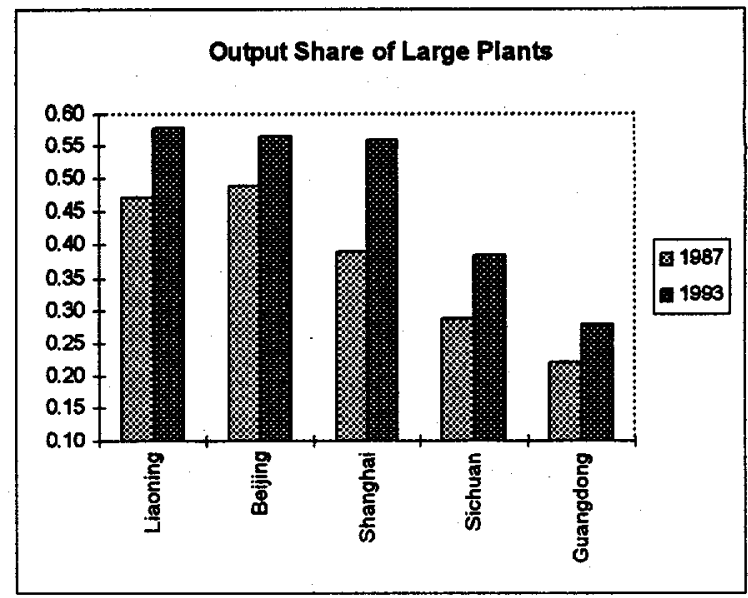

Figure 13: Industrial Output Shares for Large Plants

\section{Plant Scale}

To illustrate the impact of the reforms on industrial pollution, we begin with plant scale. Figure 13 portrays total industrial output shares for large plants in our five provinces. There is a clear, consistent pattern of increase in plant scale during the period 1988-1993, which is most pronounced for Shanghai. Our analysis has shown that this increase in scale has been accompanied by a substantial decline in pollution intensity. ${ }^{8}$

\section{Ownership}

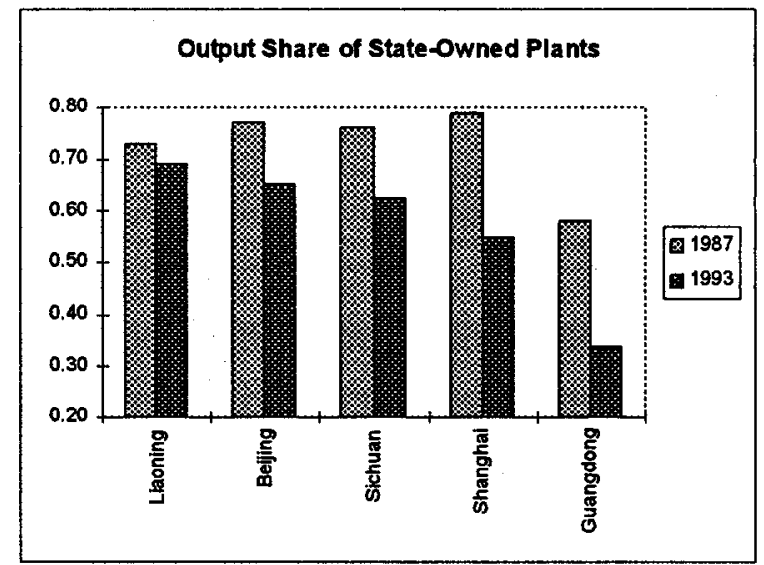

Figure 14: Output Shares for SOE's

Across our five provinces, Figure 14 shows that there has been a large decline in the output share from SOE's during the reform period. The decline is most pronounced in Shanghai and Guangdong. Our econometric results suggest that the decline in SOE share has been accompanied by a significant decline in pollution intensity.

\footnotetext{
${ }^{8}$ These results are representative of changes in China as a whole. See Wang and Wheeler (1996) for an analysis of changes in industrial water pollution across all of China's provinces.
} 


\section{Sectoral Change}

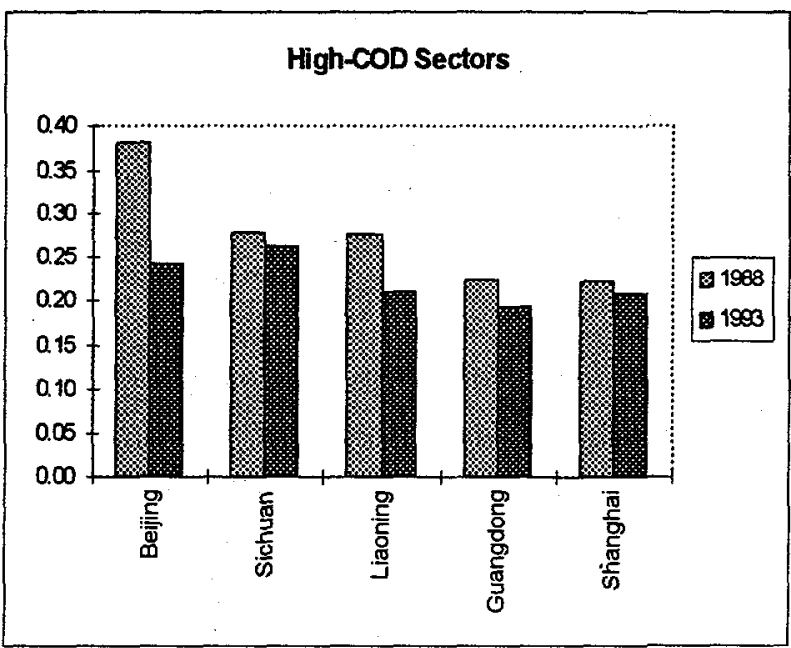

Figure 15: Production Share of COD-Intensive Sectors
Figures 15 and 16 provide information on the share of production in 'dirty' sectors across our five provinces, and for China as a whole. For China, only SO2intensive sectors have exhibited a significant drop in share since 1987 . In our five provinces, however, the reforms have had a more general 'clean' effect. The dirty sector share drops in all cases for water pollution and in all but one case (SO2 in Liaoning) for air pollution. The largest changes have occurred in Beijing for COD-intensive sectors, and in Guangdong and Shanghai for both SO2and TSP-intensive sectors.

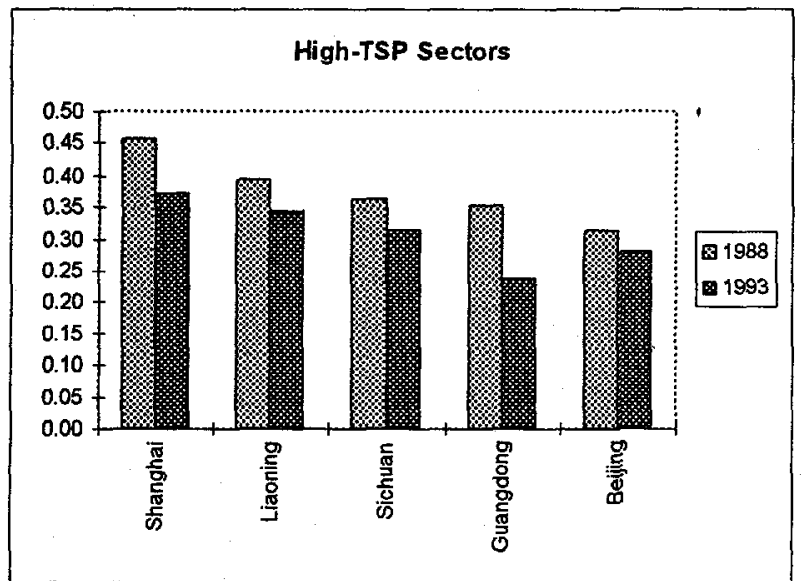

Figure 16: Production Share of SO2-and TSPIntensive Sectors

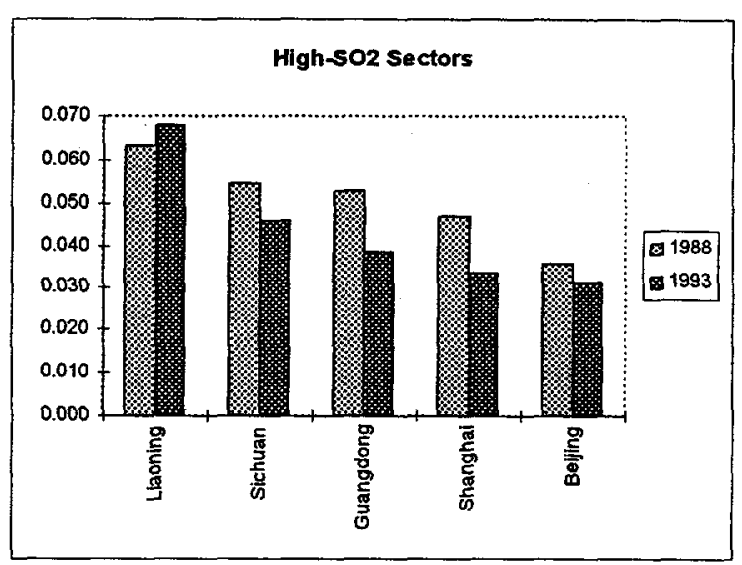

\section{Trade Liberalization}

China has opened its frontiers to more trade as the economic reforms have proceeded. From an analytical perspective, the impact of trade liberalization on the environment could be either positive or negative. Positive effects include enhanced production efficiency in export-oriented enterprises and more rapid absorption of newer, cleaner technologies from OECD sources. ${ }^{9}$ On the other hand, China's comparative advantage could be in pollutionintensive industries because it has weaker environmental regulation and lower-cost heavy raw materials than many of its trading partners. We have checked for this possibility by

\footnotetext{
${ }^{9}$ Huq, Martin, and Wheeler (1993) have found that more open developing economies absorb clean technologies in metals and paper production much more rapidly than their less open counterparts.
} 


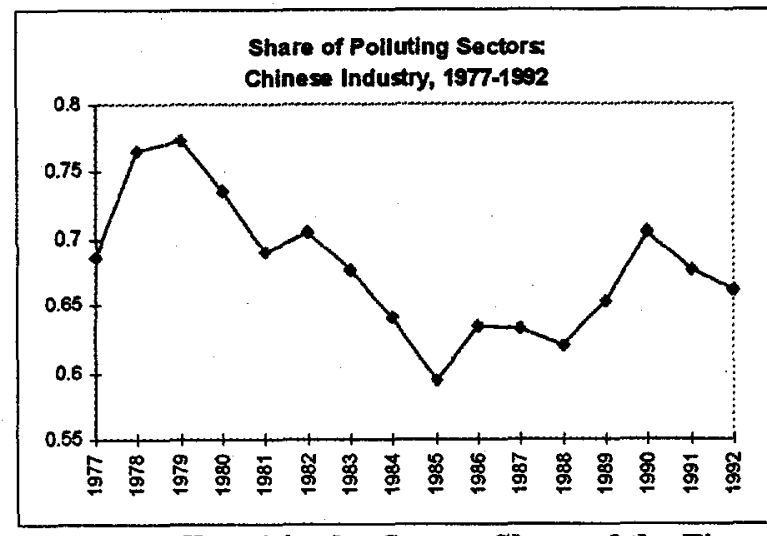

Figure 17: Trend in the Output Share of the Five Dirtiest Industry Sectors

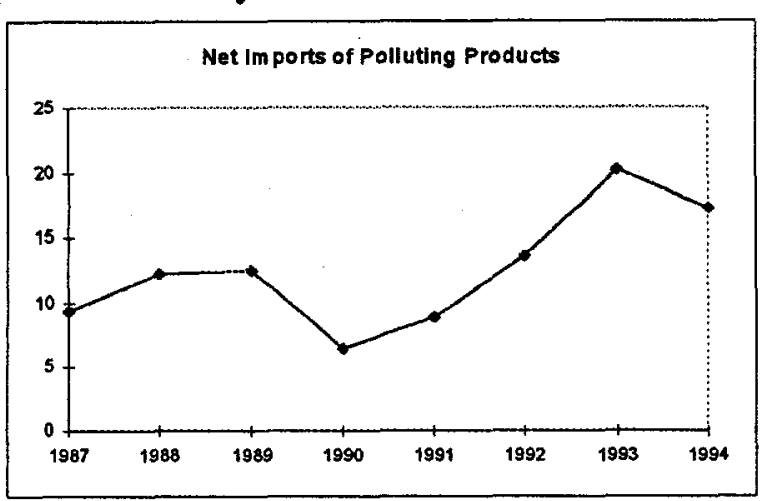

Figure 18: Trend in Net Imports from PollutionIntensive Industries

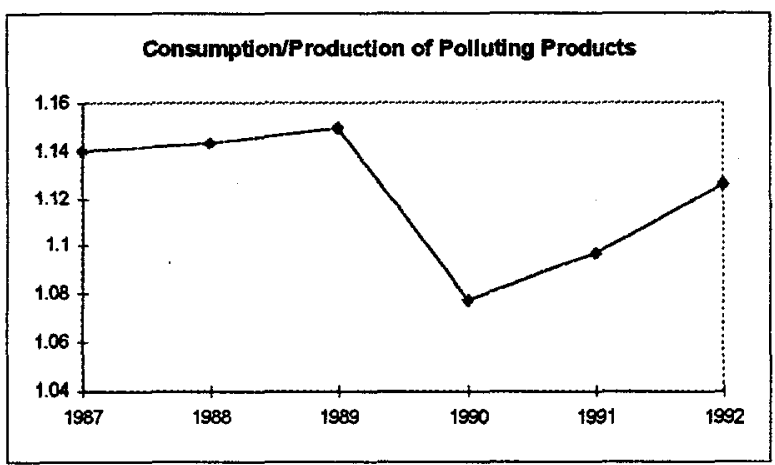

Figure 19: Consumption/Production for the Output of Pollution-Intensive Industries analyzing recent trends for the five most heavily-polluting industry sectors: ${ }^{10}$ Chemicals, Pulp and Paper, Non-Ferrous Metals, Ferrous Metals, and Non-Metallic Minerals (principally Cement). Using production and trade data for China and its trading partners, we have developed three indices of change in pollution intensity.

The first is the proportion of China's total industrial output produced by these five sectors during the era of reform. Figure 17 provides the evidence: From 1977 to 1992 , the output share of the five 'dirty' sectors has trended downward. Within the period, rapid decline in the early 1980 's was succeeded by an increase in the late 1980's and a leveling off in the early 1990s. There is no evidence of any long-run shift toward a pollution-intensive industry structure.

Our second index is the trend in net imports (imports minus exports) of products from the five heavily-polluting sectors. If China's comparative advantage is really in pollution-intensive industries, then the era of trade liberalization should be witnessing a shift toward net exports of their products. In fact, Figure 18 shows that the opposite has occurred: Real net imports of these products have trended strongly upward since 1987.

Finally, we have used the available data to calculate China's

consumption/production ratio for the output of the five dirty sectors. If China's comparative advantage lies in 'dirty' production, then two things should be true. First, this ratio should be less than one, since China should be a net exporter of pollutionintensive goods. Secondly, the ratio should fall over time because production for export should increase faster than production for domestic consumption. The evidence is Figure 19 is mixed, but is not generally consistent with the hypothesis that China's comparative advantage is in pollution-intensive production. The series has a modest downward trend

${ }^{10}$ See Hettige, et. al. (1995) and Mani and Wheeler (1997) for detailed information on pollution intensities by sector. 
for the period since 1987. However, the consumption/production ratio has remained well above one throughout the period. This supports the story in Figure 18: China has been and remains a net importer of pollution-intensive goods from its trading partners.

Overall, the evidence seems clear: China's revealed comparative advantage in the era of trade liberalization has been in non-pollution-intensive goods. Of course, all industries have experienced rapid growth during the past ten years, including pollution-intensive ones. Their cleaner counterparts have simply grown faster, both in the domestic sphere and in China's international trade. The comparative advantage effect of trade liberalization has therefore reinforced its positive impact on efficiency and absorption of clean technology. For China, increasing openness seems to have had a generally 'clean' impact on the sectoral composition of industrial output.

\subsection{Regulation, Pollution Abatement and Industrial Migration}

Our research has identified the effective pollution levy as a powerful instrument for inducing emissions reduction by Chinese industry. ${ }^{11}$ Pollution intensity is significantly lower in provinces with higher effective levies, and it is falling in provinces where the levies are rising. However, China's recent history suggests that commitment to stricter regulation has been mixed at best. Despite the clearly damaging levels of air pollution revealed by Figure 6, real effective air pollution levies have actually fallen since 1987 in all five of our focal provinces. The decline is particularly striking in Beijing and Shanghai. Real effective water pollution levies have also fallen in these cities, while they have risen sharply in Liaoning and Guangdong (and more modestly in Sichuan).

\section{The Impact of Regulation}

Industrial air and water pollution intensity have declined in all five provinces, but at very different rates. To interpret these variations, it is useful to combine the evidence in Figures 7 and 8 . For both air and water pollution, declining real levies in Beijing and Shanghai have produced incentives for increased pollution intensity. The observed declines in intensity are therefore attributable to countervailing shifts in scale, ownership and sectoral composition induced by the economic reforms. For air pollution intensity, the same conclusion follows for Liaoning, Guangdong and Sichuan: The decline is due to the structural impact of reform, because the air pollution levy has actually fallen in real terms. In the case of water pollution, on the other hand, there has been a sharp drop in intensity in these three provinces because the two factors have reinforced one another: Effective water pollution levies have risen substantially, and the structural impact of reforms has been strongly pollution-reducing.

${ }^{11}$ See Wang and Wheeler (1996) and the Appendix for evidence on the water pollution levy. Corresponding evidence for the air pollution levy is provided in the Appendix. 


\section{Migration of Dirty Sectors Within China?}

In the previous section, we established that trade reforms have not had a 'dirty-sector' bias during the past decade. However, it is at least possible that internal differences in regulatory strictness could have induced relocation of dirty industry within China. Despite the evident trend toward equalization of the effective levy in the eastern provinces, Figure 8 includes differences as great as 3:1 in levy rates. Lucas (1996) has recently investigated whether such differences have induced faster growth of pollutionintensive sectors in provinces with laxer regulation. His results suggest that differential levies are not significant as location factors, so there has apparently been no regulationinduced migration of dirty sectors within China. ${ }^{12}$

\section{Economic Reform and The Cost of Abatement}

In recent econometric research, we have used plant-level data from NEPA to develop detailed estimates of abatement costs for air and water emissions by Chinese industry (Appendix; Dasgupta, Huq, Wheeler and Zhang, 1996). Our results show that marginal abatement costs (MAC) vary greatly by sector, scale, abatement rate, ownership, and pollutant. The impact of these variables on marginal cost is dramatically illustrated by a few comparisons. Holding other factors constant, MAC ratios can vary as much as 20:1 between large and small facilities; $45: 1$ across sectors; $13: 1$ between $10 \%$ and $90 \%$ abatement; $5: 1$ between state-owned plants (SOE's) and non-SOE's; and 4:1 across pollutants. The range of potential variation is revealed by the comparative MAC schedules in Figure 20. In the case of particulates (20(a)-(b)), MAC for large, nonSOE plants is barely above $\$ 10 /$ ton at $90 \%$ abatement. By contrast, large SOE facilities reach the same MAC at $40 \%$ abatement and increase to $\$ 70 /$ ton at $90 \%$. For small plants, MAC's for particulates increase by an order of magnitude in both cases: to over \$200/ton for non-SOE's and \$1,400/ton for SOE's.

${ }^{12}$ See Lucas (1996) (20a)

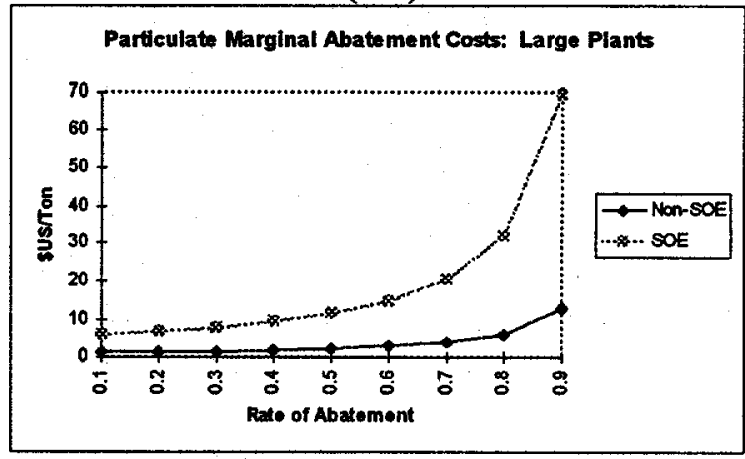

Figure 20: Marginal Abatement Costs for Chinese Industry

(20b)

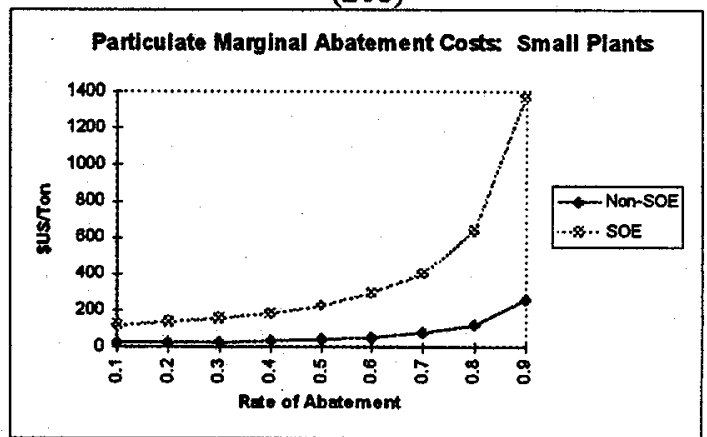


Figures $2 \mathrm{O}_{i}$ (c)-(d) tell the same relative story for $\mathrm{SO} 2$ abatement, but the MAC schedules shift upward by half an order of magnitude. At $90 \%$ abatement, MAC's are approximately $\$ 50 /$ ton for large, non-SOE plants; $\$ 280 /$ ton for large SOE's; $\$ 1,000 /$ ton for small nonSOE's; and $\$ 5,500 /$ ton for small SOE's.

(20c)

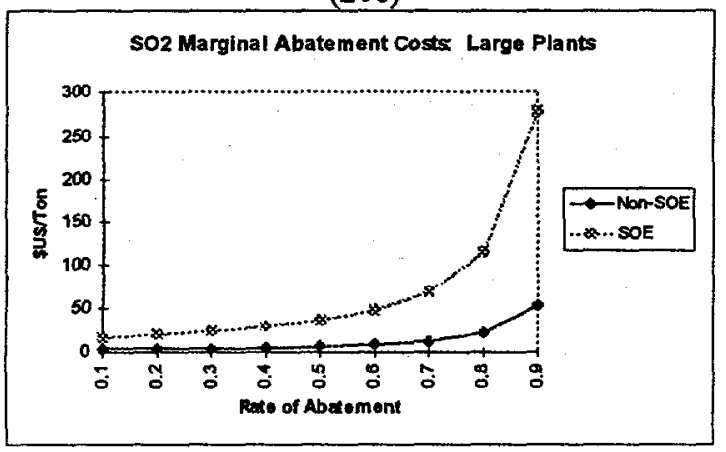

(20d)

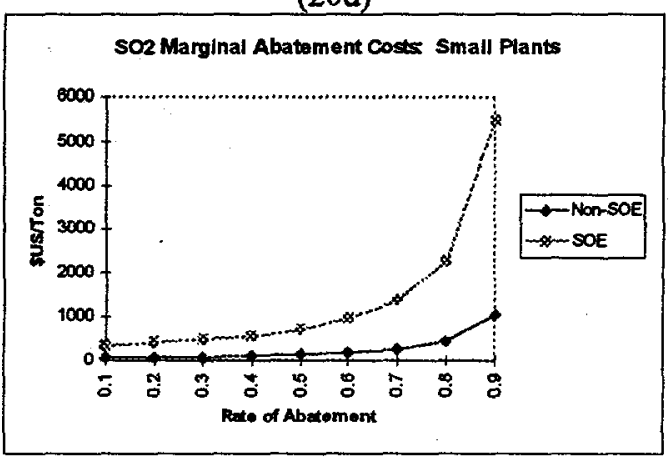

These dramatic differences highlight the beneficial impact of economic reform on China's prospects for industrial pollution control. As an increasing share of industrial production moves toward large non-SOE plants, the marginal cost of abatement for the industrial system is falling significantly. Our results suggest that the marginal cost of abatement is now substantially lower (in real terms) than it was in 1987.

\subsection{The Role of Local Communities}

During the era of reform, incomes have risen rapidly across China (Figure 4) and literacy rates have continued to improve. Our research on regulation in China suggests that these developments have also had a significant effect on industrial water pollution. As local communities have become wealthier and better-educated, three forces for declining pollution intensity have been strengthened. First, increased community income and education push the water levy rates upward as provincial regulators adjust their enforcement policy to improved conditions and higher valuation of environmental benefits. Secondly, feedback through citizen environmental complaints increases, with amplifying effects on enforcement. Finally, rising income and education strengthen 'informal regulation,' as communities with more resources and greater interest in environmental protection increase pressure for abatement through a variety of political and social channels.

While the link between socioeconomic development and effective water pollution levies seems clear, we have found no equivalent empirical relationship between development and effective air pollution levies. This is unfortunate, because the evidence suggests that air pollution, not water pollution, is the major source of damage to human health in China. In fact, our evidence shows that real air pollution levies have been declining all over China during a period of rapid growth and otherwise-progressive change. The implication is clear and sobering: Nothing in the Chinese system will automatically guarantee stricter 
regulation of air pollution as the economy advances. If current trends continue, many thousands of lives will be lost to air pollution in China's industrial centers.

To summarize, several factors have strongly affected industry's environmental performance in China during the past decade. For China's environmental regulators, important policy options are identified by the direct impact of regulation on emissions and the use of public environmental information to bolster informal regulation by local communities. National and provincial economic reforms also have a major impact on polluters' behavior and abatement costs, through their effects on the sectoral growth rates, plant ownership and scale of operations. Finally, more general economic development policies influence industry's environmental performance in the long run by increasing community incomes, education levels, and bargaining power. These feed back into regulation, both formally (through citizen complaints and the enforcement policy of regulators) and 'informally' (through increased pressure on plants from local communities).

\section{Designing Future Pollution Scenarios}

\subsection{The Past as Prelude}

Our review of recent Chinese experience with industrial pollution shows that significant progress in abatement is possible. In cases where regulatory incentives to abate have complemented the progressive impact of economic reforms, there have been rapid declines in the pollution intensity of production - so rapid, in fact, that total water pollution loads from regulated industries have actually fallen. ${ }^{13}$ But in many cases, particularly for hazardous air pollution, the recent trend in regulatory incentives has been perverse: Effective levies have declined significantly, producing an inducement to higher pollution intensity which has canceled much of the impact of the reforms. Furthermore, the reforms themselves will inevitably run their course: Increases in the output shares of large and non-SOE factories are naturally self-limiting. While the reforms have certainly 'bought time' for China, the future spotlight must shift to the prospects for tighter regulation. If abatement incentives aren't adjusted, industrial pollution intensities, pollution loads and contamination of the ambient environment will almost certainly increase. Given China's current industrial growth rate, the consequences for public health could be severe. In this section, we use our econometric results to project the consequences of alternative policy strategies for China's environmental future.

${ }^{13}$ It is less clear that overall loads from industry have fallen, because much production in rapidly-growing TVIE's is apparently not covered by the traditional regulatory system. The evidence for TVIE's is extremely scanty, and research on the environmental performance of TVIE's is clearly a top priority for future work. 


\subsection{Projecting the Pollution Impact of Alternative Policies}

China affords a unique opportunity for projection of alternative futures, because for many parts of China the future already exists. As Figures 8, 13 and 14 indicate, China's provinces and major urban areas exhibit great disparity in the present strictness of environmental regulation, the share of production in large enterprises, and the degree of state ownership of industry. Shanghai, for example, has a high proportion of production in large facilities, a low proportion in state enterprises, a high (although unfortunately, falling) degree of regulatory strictness and, as a result, low levels of pollution intensity per unit of industrial output. Sichuan's statistics are the converse in most cases.

For much of China, it will be many years before current conditions in Shanghai are replicated. Thus, although we cannot predict the future path of technological progress with any accuracy, we can develop conservative projections for much of China based on actual conditions in the more advanced provinces. And even among the latter, there is sufficient diversity of characteristics to permit use of econometrically-estimated relationships to estimate the consequences of moving toward leading-edge status in the dimensions which matter most for pollution intensity.

China's second advantage is its wealth of data. Large databases made available to us by NEPA have enabled us to base our entire forecasting exercise on the econometric estimation exercises summarized in this paper. To our knowledge this has not previously been possible, in China or any other country. We have used the NEPA databases in three related studies: (1) determinants of industrial air and water pollution intensity; (2) the impact of air emissions on atmospheric pollutant concentrations; and (3) the cost of pollution abatement. For our air pollution scenarios, we have completed the forecasting exercise by joining our estimates to the empirical findings of Xu. et. al. (1994) on the health impact of air pollution.

\subsection{Projecting Pollution Damage}

\section{Emissions Intensities and Loads}

Our analysis begins with projections of industrial pollution loads, which are based on our econometric studies of variations in pollution intensity for $\mathrm{COD}, \mathrm{SO} 2$ and TSP. Figures 11 and 12 summarize the significant intensity factors: The effective pollution levy; large plant share of output; SOE share of output; and the shares of exceptionally 'clean' and 'dirty' sectors. Assuming that the economic reforms will continue, we have extrapolated from recent trends in these variables to project their future paths.

We treat the effective pollution levy as a policy variable in three scenarios: (1) Holding the air and water pollution levies constant at their 1993 levels, which would represent regress for water but progress for air (in light of the decline since 1987); (2) an annual increase of $5 \% / y e a r$, which would be approximately reflect the recent national trend for water 
pollution levy rates and a considerable reversal of trend for air pollution; (3) an annual increase in $10 \%$ per year, representing a much stronger commitment to pollution control. ${ }^{14}$

We combine these three levy scenarios with projected changes in sector, output scale and ownership to generate projected paths for industrial COD, SO2 and TSP intensity for China as a whole, and for the major cities in our five focal provinces: Beijing, Shanghai, Shenyang (Liaoning), Guangzhou (Guangdong), and Chongqing (Sichuan). These are combined with exogenously-projected changes in total industrial output to produce estimates of future air and water pollution loads. ${ }^{15}$

\section{Ambient Concentration}

We use the econometric results illustrated in Figure 1 to project the consequences of changing air pollution loads for ambient concentrations of $\mathrm{SO} 2 .{ }^{16}$ Controlling for precipitation, the estimated elasticity linking load to concentration is approximately .51 : A $1 \%$ increase in $\mathrm{SO} 2$ emissions density (or emissions per unit area) in a particular city increases its atmospheric concentration by .51\%. We use this elasticity and the projected air emissions change in each city to project future atmospheric concentrations. We have not been able to replicate the exercise for suspended particulates or water pollution, because supporting data are not available.

\section{Health Damage}

The next link in the analytical chain requires estimation of the change in mortality which is induced by a change in atmospheric $\mathrm{SO} 2$ concentration. For this exercise, we rely on recent empirical studies in Beijing and Shenyang by Xu, et. al. (1994). They have estimated 'dose-response' relationships linking atmospheric concentrations of TSP and $\mathrm{SO} 2$ to respiratory disease in the two cities. They find the strongest relationship between mortality and ambient $\mathrm{SO} 2$ concentration, but with high variability: Mortality responds much more strongly to $\mathrm{SO} 2$ concentration change in Beijing than in Shenyang. For these two cities, we have projected health risks using the dose-response parameters estimated by $\mathrm{Xu}$ 's team. For the other three cities, we have used the average of the two parameter values. In each case, we have estimated mortality risks from projected atmospheric SO2 concentrations, and combined the risk estimates with projected city populations to forecast changes in mortality from respiratory illness.

Our projections focus on $\mathrm{SO} 2$ concentrations because Xu's study shows that they are highly correlated with damage from respiratory disease. Recent scientific evidence provides some insight into the nature of this relationship. Sulfur dioxide and other oxides

\footnotetext{
${ }^{14}$ NEPA has recently recommended a tenfold increase in the air pollution levy rate, which would be in the same range as our $10 \%$ annual increase scenario.

${ }^{15}$ We assume that growth rates of pollution loads for the five cities are the same as the projected rates for their provinces. For Beijing and Shanghai, this is a tautology. The assumption seems quite reasonable in the other cases, since the three cities are the primary industrial regions of their respective provinces.

${ }^{16}$ Full econometric results are reported in the Appendix.
} 
of sulfur combine with oxygen to form sulfates, and with water vapor to form aerosols of sulfurous and sulfuric acid. These acid mists can irritate the respiratory systems of humans and animals. Therefore, a high concentration of $\mathrm{SO} 2$ can affect breathing, and may aggravate existing respiratory and cardiovascular disease. Sensitive populations include asthmatics, individuals with bronchitis or emphysema, children, and the elderly.

The second, and probably more significant, effect of $\mathrm{SO}_{2}$ is traceable to the impact of fine particulates on mortality and morbidity. A review of recent evidence by the US Environmental Protection Agency suggests that fine particulates are the source of the worst health damage from air pollution. In the case of China, there is reason to believe that $30-40 \%$ of fine particulates are in the form of sulfates from SO2 emissions.

While Xu's results and the available data have led us to focus on SO2, we also recognize the potential contribution of total suspended particulates (TSP) to atmospheric concentrations of fine particulates (FP). For Beijing and Shenyang, we interpret Xu's weak results for TSP to mean that measured total suspended particulates in those cities do not have a substantial FP component. Nevertheless, we recognize that this may not be true in other cases. Therefore, our policy scenarios include projections for industrial TSP emissions, both for China as a whole and for our five cities.

\subsection{Projecting Abatement Costs}

Abatement costs are projected from our econometric analyses of Chinese factory data for several air and water pollutants. The major determinants are pollutant type; industry sector; ownership; scale of abatement activity (related to the volume of discharge); pollutant concentration in the waste stream; and degree of abatement (or percent reduction in pollutant concentration). At the city level, we use our results to project incremental costs for degrees of abatement ranging from $10 \%$ to $90 \%$.

Data on fine particulate emissions are not available, so we have used $\mathrm{SO} 2$ as a proxy because $\mathrm{SO} 2$ emissions have a significant fine particulate content. However, as Figure 20 shows, $\mathrm{SO} 2$ reduction is considerably more expensive than abatement of particulates. To avoid severe bias in our benefit/cost assessment, we therefore consider the costs of air pollution abatement for both $\mathrm{SO} 2$ and particulates. We recognize that our analysis understates the benefits of direct removal of fine particulates, since these represent only a part of total volume for $\mathrm{SO} 2$. In any case, our results provide an extremely strong benefit/cost rationale for air pollution abatement. 


\section{Policy Choices and Environmental Consequences: Scenarios for Five Cities}

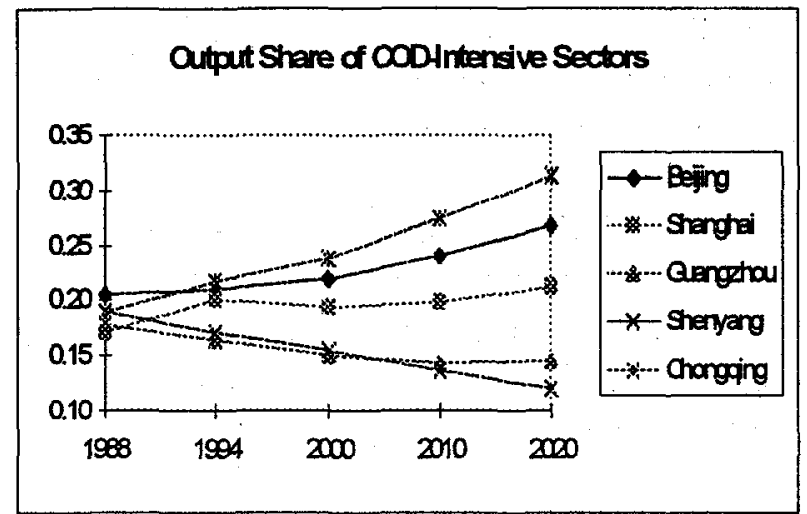

Figure 21: Changing Shares for Pollution-Intensive Sectors, 1988-2020
During the past decade, decisions on the pace of economic reform and local environmental regulation have significantly affected the pollution intensity of industrial production in China. Because they reflect much of China's regional variety, our five cities provide a good focus for exploring the past results of these policies and their implications for future environmental conditions. To provide overall perspective, we also include projected pollution intensities and loads for China as a whole.

\subsection{Trends in Pollution Intensity Factors}

In the first stage of the analysis, we use recent trends to project future levels of non-regulatory determinants of pollution intensity (pollution per unit of output) for $\mathrm{COD}, \mathrm{SO} 2$ and TSP. At the national level, we project the share of COD-intensive sectors to remain constant at $20 \%$ between 1994 and 2020; the share for SO2intensive sectors to drop from $6.6 \%$ to $4.7 \%$, and the TSP-intensive share to increase very slightly, from $32 \%$ to $32.8 \%$. While only the $\mathrm{SO} 2$-related changes appear significant at the national level, Figure 21 suggests increasing diversity in the structure of regional production. All pollution-intensive sectors have a rising output share in Beijing and a falling share in Guangdong. Liaoning has rising $\mathrm{SO} 2-$ and TSP-intensive shares, but falling share for COD-intensive production. The pattern in Shanghai and Sichuan is mixed, with rising COD- and TSP-intensive shares but a falling $\mathrm{SO} 2$-intensive share. Although these impacts are unintentional, they are part of 'business as usual' under the reform. On this margin, provinces
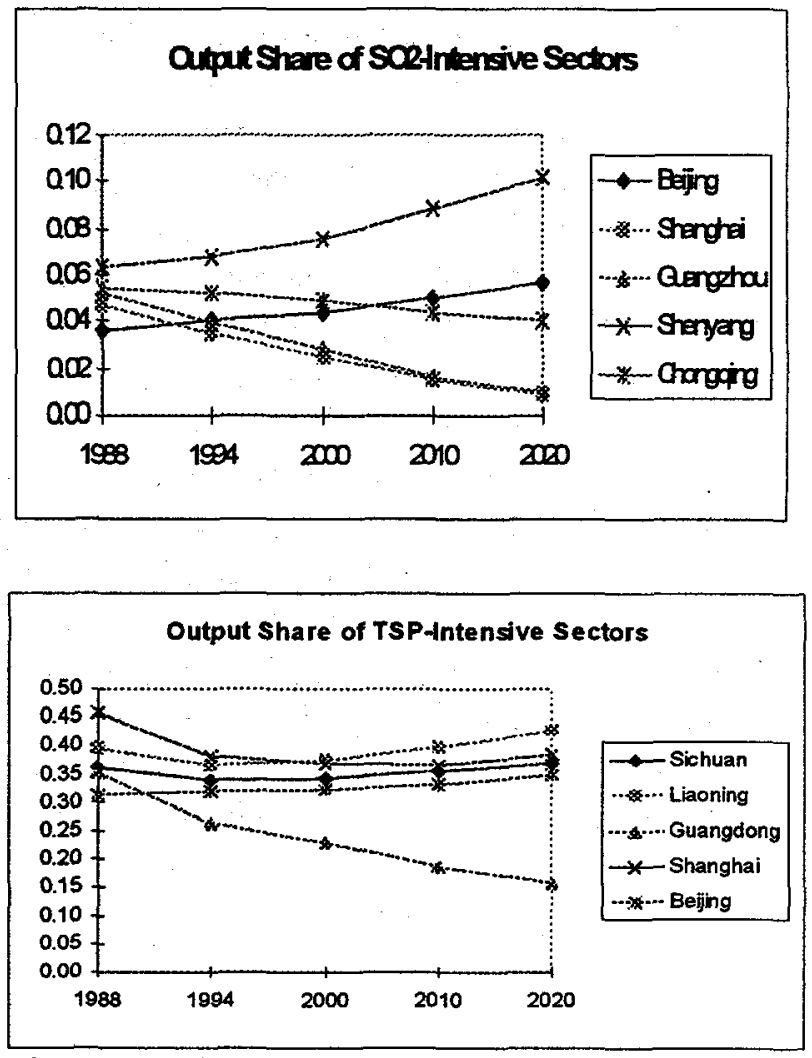

Figure 21: Changing Shares for Pollution-Intensive Sectors, 1988-2020 
with a rising share of pollution-intensive output will carry a heavier regulatory burden than those with a falling share. The environmental impact of changing shares is reflected in our projections. $^{17}$

Recent trends suggest less diversity in the movement toward concentration of production in large plants. Shares in all five cities are trending upward at about the same rate, so the projected distribution across provinces in 2020 has a spread similar to the current one. Cities in the northeast group (Beijing, Shanghai, Shenyang) are tightly clustered around one path; Guangzhou and Chongqing around another. Figures 22 (a-b) display a striking

22(a)

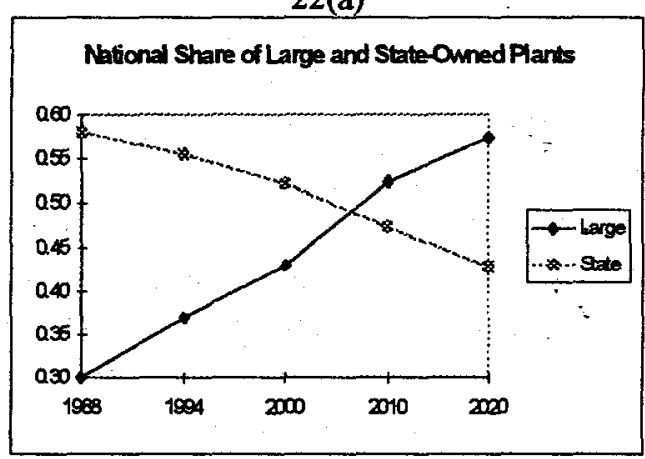

22(b)

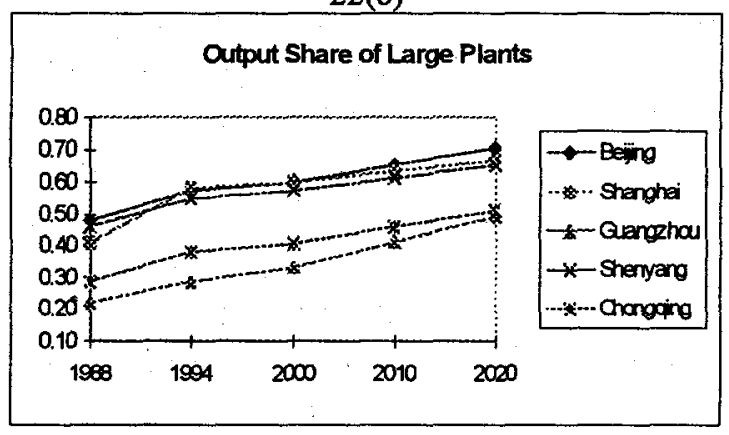

increase in projected shares: For China as a whole, the large-plant share increases from $30 \%$ to $58 \%$ during the period $1988-2020$. Across provinces; the minimum large-plant share rises from $22 \%$ to $49 \%$ (Guangdong), while the maximum increases from $48 \%$ to $70 \%$ (Beijing). While they forecast large changes, our projections are mostly within the range of current experience.

For state ownership, the projections illustrated in Figure 22 (a-c) show a continued sharp decline at the national level, but a more mixed experience across provinces. Extrapolation from recent trends yields a projected national decline in SOE share from $58 \%$ to $43 \%$ during the period $1988-2020$. Beijing, Shanghai and Chongqing experience a similar decline in SOE share: From around $70 \%$ in 1988 to around $40 \%$ in 2020 . Guangzhou preserves its status as a strong non-SOE 'outlier,' declining from an already-low SOE share of $45 \%$ in 1988 to around $15 \%$ in 2020 . Shenyang, on the other (22c)

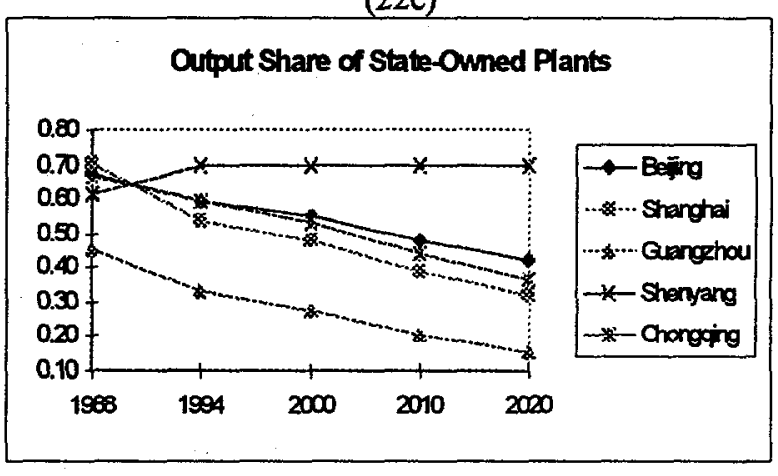
hand, had an actual increase in SOE share during 1988-1994. While we do not expect this to continue, we have no evidence to support a projection of declining SOE

17 As previously noted, the 'pollution intensive' sectors in this analysis are the sectors with large 'dirty" or 'clean' residual effects after size, ownership and provincial pollution levies are accounted for. 
share in Shenyang. We therefore assume that it will remain stable at its current level perhaps overly conservative, but consistent with our approach for other cities.

\subsection{Industrial Production}

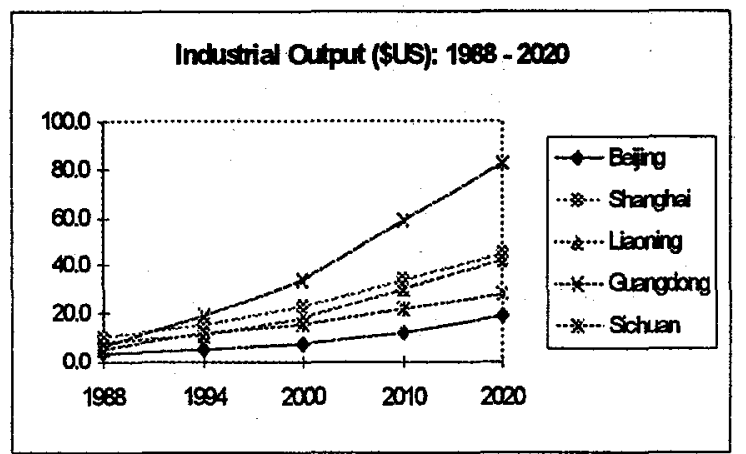

Figure 23: Industrial Output Trends, 1988-2020
Total discharge for a pollutant is the product of pollution intensity (or pollution per unit of output) and output. Obviously, projected output scale is a critical predictor of future pollution problems. China's overall industrial growth rate has been among the highest in the world during the past decade, and we forecast that it will slacken somewhat in the early twentyfirst century. Again, an analysis of regional trends reveals considerable

diversity within China (Figure 23). Shanghai's industrial economy is already huge, and its economy is shifting rapidly toward the service sector at the margin. Extrapolating from the trend during 1988-1994, we project a 4.1\% annual growth rate for Shanghai's industry through 2020; an overall increase of about $180 \%$ during the forecasting period. Guangdong has a projected industrial growth rate of 5.7\% and an overall increase of $320 \%$. Beijing and Liaoning are intermediate, with annual growth rates near 5\% and overall increases of around $250 \%$. The contrast between the coastal regions and the interior is evident in Sichuan's trend output growth. Although our projection (3.5\% annual; $150 \%$ overall) would be respectable for many economies, it is clearly lagging by comparison with the coastal provinces.

Of course, these simple extrapolations cannot fully anticipate the dynamics of regional change during the next two decades. It is entirely possible that congestion and rising factor costs in the coastal region will reduce its comparative advantage for industrial location, leading to a shift toward interior locations. However, agglomeration economies are powerful and the coastal region is China's entrepot for international trade. On balance, extrapolations from recent trends seem to yield reasonable predictions.

\subsection{Economic Reform and Environmental Regulation: Possible Futures}

\section{Prospects for 'Win-Win': Economic Reform Without Stricter Regulation}

China's economic reforms have generated powerful forces for reduced pollution intensity in manufacturing. The consolidation of production in large plants has lowered pollution intensity, because unit abatement costs and generation of waste residuals are lower in large facilities. Non-SOE factories have absorbed a growing share of industrial output, producing further reductions in pollution intensity from efficiency gains. Our econometric analysis suggests that these factors have accounted for much of the decline in air and 
water pollution intensity across China's provinces since 1987. The experience of regulation has been more mixed: Higher air- and water-pollution levies have significantly reduced pollution intensity, but real effective air levies have actually fallen in all five focal provinces since 1987 and the water levies have fallen in Beijing and Shanghai.

The results have been equally mixed. In Guangdong, where increases in the water levy have reinforced the impact of reform (including a decline in the share of COD-intensive sectors), there has been a very sharp decline in water pollution intensity. In Beijing, by contrast, the effective air pollution levy has fallen substantially while the share of SO2-and TSP-intensive sectors has risen. These changes have partly counteracted the impact of the reforms, and industrial SO2- and TSP-intensities have declined modestly while production scale has risen rapidly.

What would happen in the future if the reforms continued but regulation wasn't tightened? To explore this possibility, we have combined our econometrically-estimated intensity equations for COD, SO2 and TSP with projected changes in pollution intensity factors (sector, scale, ownership), while holding air and water pollution levies at 1993 levels for each province. This is equivalent to projecting the environmental consequences of continued economic reform alone, with no contribution from stricter regulation. We term this the 'win-win' scenario because economic reform is already presumed to be beneficial on other grounds. Its impact on pollution intensity provides a net environmental gain without any cost explicitly incurred for pollution control.

\section{Tightening Regulation: Two Scenarios}

Tightening regulation will provide explicit incentives to reduce pollution intensity, which will complement the impact of economic reform. To explore the implications of different strategies, we have developed two scenarios: In the first, air and water pollution levies are both increased by 5\% annually. This leads to a fourfold increase in the real levy by 2020 . A second scenario increases levies by $10 \%$ annually, leading to a thirteenfold increase by 2020.

\section{Water Pollution}

Comparative forecasts for total COD load are presented for China as a whole and by city in Figure 24. The projected impact of continued reform alone (the 'win-win' scenario) is remarkable. For China, total COD emissions from industry are projected to rise only modestly, from 8.3 million tons annually to 9.8 million tons, during a period of rapid industrial growth. In three of the five cities - Shanghai, Guangzhou and Shenyang -- 
projected changes in sectoral composition, scale and ownership are sufficient to maintain or reduce total COD loads. For two cities - Beijing and Chongqing - COD discharges increase, but at a far slower rate than industrial output.
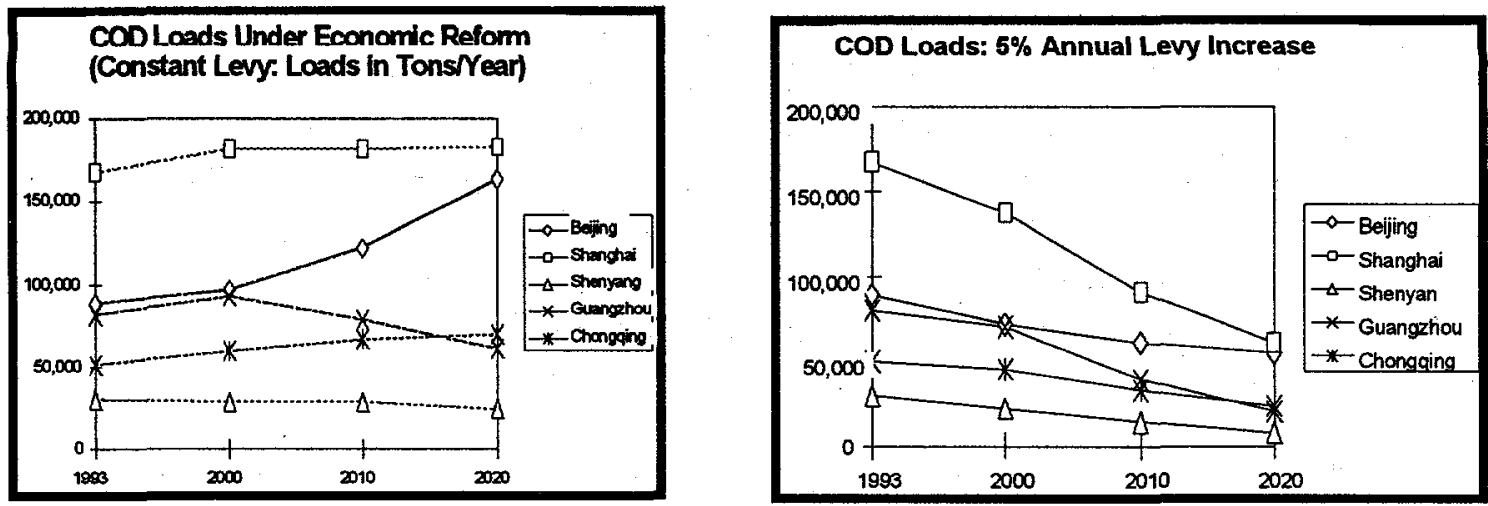

Figure 24: COD Loads in Three Scenarios (cont'd)

Our first (5\%) levy scenario reflects a continuation of recent trends in water pollution regulation. The results for China are very encouraging: a projected reduction from 8.3 million tons to 3.3 million tons. In the five cities, a fourfold increase in the effective levy (coupled with the reforms) induces a COD load reduction of $66 \%$. This amounts to over 120,000 tons annually in Shanghai alone. The imposition of a $10 \%$ annual increase in the levy leads to a fall in emissions from 8.3 million tons to 1.1 million tons nationally and $88 \%$ reductions for the five cities: 160,000 tons annually in Shanghai, 145,000 in Beijing; 60,000 in Chongqing, 55,000 in Guangzhou and 21,000 in Shenyang.

All three scenarios lead us to an optimistic view of the potential for solving China's industrial water pollution problem, at least in the case of COD. The best available evidence suggests that total COD loads will increase only modestly as economic reform proceeds, even if regulations are not tightened. Moreover, the projected results of higher pollution levies are quite striking. We project that a $10 \%$ annual increase in the levy through 2020 would eliminate most of the COD emissions from regulated factories in China.

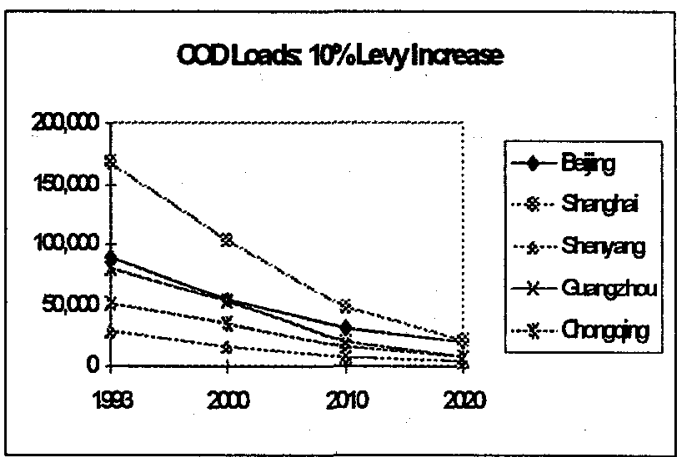

Figure 24: COD Loads in Three Scenarios

\section{Air Pollution}

For TSP and SO2, we project national and city emissions using the same approach:

- We use projected pollution levies and shares of large plants, SOE's, 'dirty' sectors and 'clean' sectors to project national and provincial pollution intensities. We assume that 
provincial intensities are the same as the pollution intensities of our focal cities (not an unreasonable assumption, since these cities are the main industrial centers of their provinces and, in two cases (Beijing and Shanghai) are identical to the provinces).

- To estimate city emissions, we multiply projected provincial industrial output by the city's share of provincial industrial output in 1993. Thus, we assume (again, not unreasonably) that the growth of industry in the province's main industrial city will be identical to the growth of industry in the province.

- To obtain total projected TSP and SO2 loads for China and the five cities, we multiply projected pollution intensities by projected industrial outputs.

For $\mathrm{SO} 2$, the available information permits us to go several steps further:

- We calculate SO2 concentration in each city's atmosphere by adjusting the previous year's concentration at .51 times the rate of change of the estimated pollution load. This reflects the econometric result illustrated in Figure 1.

- We substitute the estimated concentration into the dose-response function estimated by $\mathrm{Xu}$, et. al. (1994) to obtain the probability of individual mortality from SO2 pollution in a particular city. To benchmark our estimates, we make the conservative assumption that $\mathrm{SO} 2$ concentrations below $30 \mathrm{ug} / \mathrm{m}^{3}$ are not harmful. ${ }^{18}$

- We multiply the individual mortality probability by the city's projected population to obtain the estimated number of deaths from $\mathrm{SO} 2$ pollution.

Our results on emissions are somewhat different for TSP and SO2, reflecting the underlying differences in their econometrically-estimated response elasticities. In the pure reform ('win-win') scenario, continued decline in the air pollution intensity of industrial production is not enough to offset industrial growth: Total projected SO2 emissions rise from 14.2 million tons in 1994 to 15.7 million tons in 2020; TSP emissions rise from 16.1 million tons to 17.1 million tons. In the two levy-increase scenarios, however, sharp improvements are projected at the national level. A 5\% annual increase in the levy induces reductions of SO2 and TSP emissions to 10.3 and 7.5 million tons, respectively. When the increase is raised to $10 \%$ annually, emissions fall to 6.9 and 3.6 million tons, respectively. Thus, the $10 \%$ annual levy increase is sufficient to eliminate half of SO2 emissions and three-fourths of TSP emissions by 2020 .

${ }^{18} 30 \mathrm{ug} / \mathrm{m}^{3}$ is the tightest $\mathrm{SO} 2$ standard in the world, maintained in Canada, Switzerland and Poland. By contrast, the WHO standard is 60, China's standard is 50 , and the US standard is 80 . 
(25a)

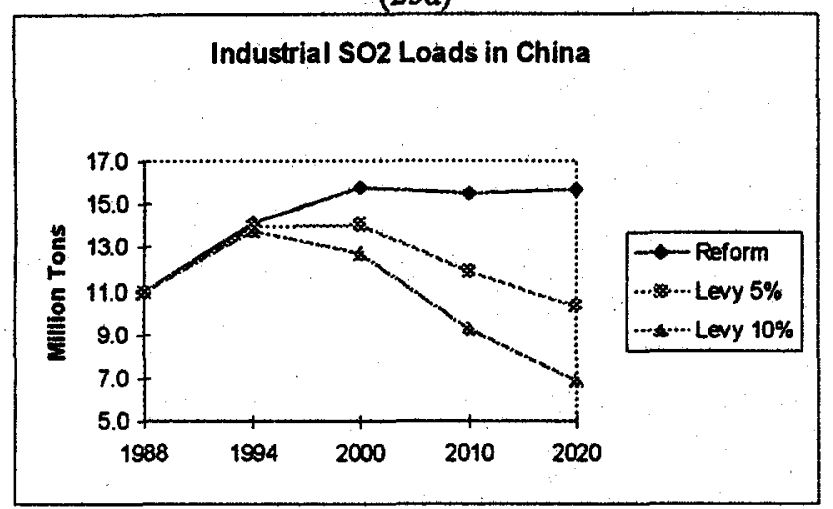

Figure 25: Air Pollutant Emissions and Concentrations in Three Scenarios
For the pure reform case, we do find that changes in scale, ownership and sectoral composition induce considerable reductions in pollution intensity. However, these are generally insufficient to prevent further deterioration in ambient air quality because of large increases in the scale of industrial production. Figure 25 illustrates the projected consequences by city: In the case of $\mathrm{SO} 2$, only Chongqing experiences a slight improvement in the pure reform

scenario, and its air quality remains terrible. Otherwise, conditions deteriorate substantially. Beijing's SO2 concentration rises from $117 \mathrm{ug} / \mathrm{m}^{3}$ in 1993 to 159 in 2020;
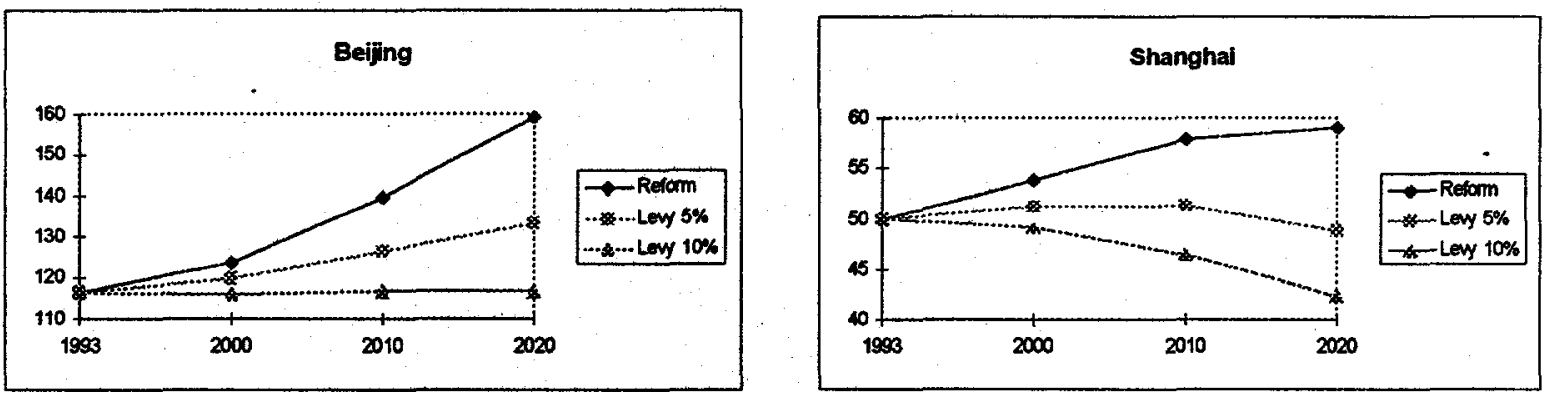

Figure 25b: Air Pollution Scenarios (cont'd)

projected annual deaths from pollution-related respiratory disease increase from 3,400 to 6,400 . Shanghai's air quality deteriorates from 50 to 59 ; , and annual deaths rise from 700 to 1,300 . Shenyang's air quality deteriorates dramatically, from 131 to 217 , and projected annual deaths rise from 800 to 1,500 . Guangzhou's $\mathrm{SO} 2$ concentration deteriorates from 47 to 54 ; deaths increase from 200 to 300 . Finally, Chongqing's slight improvement in air quality (from 270 to 264 ) produces slightly lower mortality risk for a significantly larger population, and projected deaths rise from 4,100 to 5,000 .
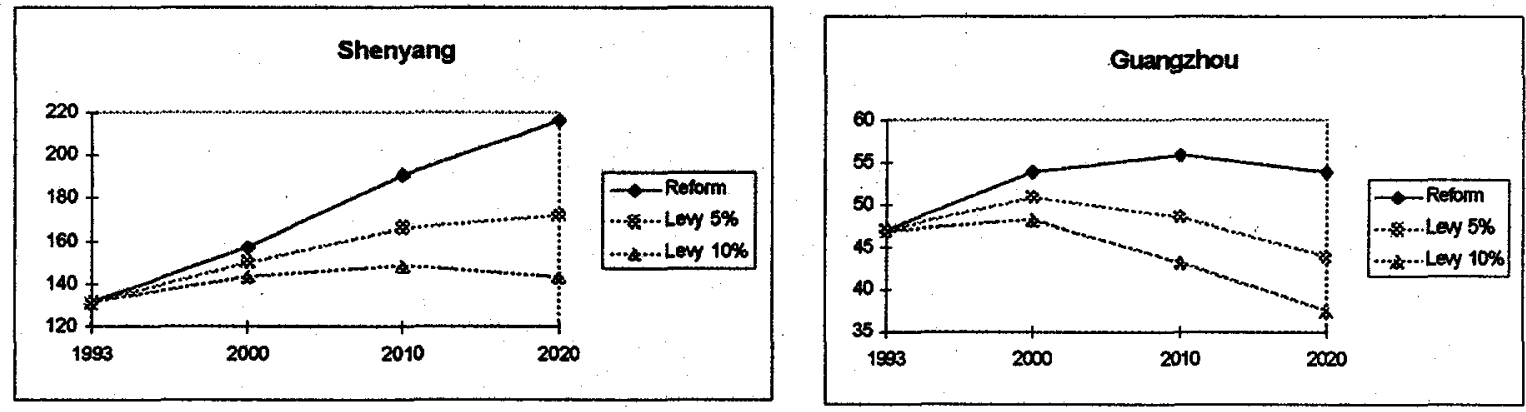

Figure 25b: Air Pollution Scenarios (cont'd) 


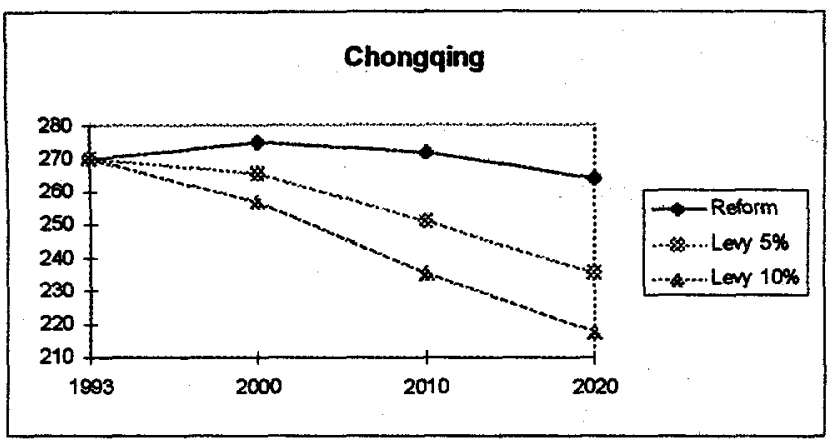

Figure 25b: Air Pollution Scenarios (cont'd)
As Figure 25 shows, a $5 \%$ annual increase in the effective air pollution levy significantly improves on the pure reform outcome in all five cities. For Guangzhou and Chongqing, air quality in 2020 is substantially better than the 1993 level. Shanghai maintains roughly constant air quality, while there is slower deterioration in Beijing and Shenyang.

Finally, we trace the projected impact of a $10 \%$ annual increase in the levy. This is sufficient for rough maintenance of the 1993 status quo in Shenyang and Beijing, while Shanghai, Guangzhou and Chongqing experience strong improvements in air quality.

As Table 5.1 shows, the projected impact of levy increases on annual deaths is quite impressive in all five cities. For the $10 \%$ levy increase, projected deaths in 2020 fall by $67 \%$ in Guangzhou, $50 \%$ in Shenyang, $47 \%$ in Beijing, 36\% in Shanghai and $31 \%$ in Chongqing.

Table 5.1: Projected Annual Deaths from Industrial SO2 Pollution ${ }^{19}$

\begin{tabular}{|l|r|r|r|c|}
\hline & Reform & Levy 5\% & Levy 10\% & $\begin{array}{l}\% \text { Decrease } \\
\text { for Levy 10\% }\end{array}$ \\
\hline Beijing & 4500 & 3200 & 2400 & 47 \\
\hline Chongqing & 3200 & 2600 & 2200 & 31 \\
\hline Shenyang & 1200 & 900 & 600 & 50 \\
\hline Shanghai & 1100 & 700 & 700 & 36 \\
\hline Guangzhou & 300 & 200 & 100 & 67 \\
\hline
\end{tabular}

Figure 25c displays changes in TSP loads for each city in our three scenarios. In the pure reform scenario, we project substantial increases in emissions for Beijing, Shanghai, and Shenyang, and rough stability in Chongqing. For the $5 \%$ and $10 \%$ levy scenarios, the projected trends generally replicate the sharp drop in TSP load which is projected at the national level. The exception is Shenyang, which experiences only a modest decline.

${ }^{19}$ Estimated deaths in the preceding paragraphs are for total $\mathrm{SO} 2$ pollution, and are therefore higher than the estimates in this table. 

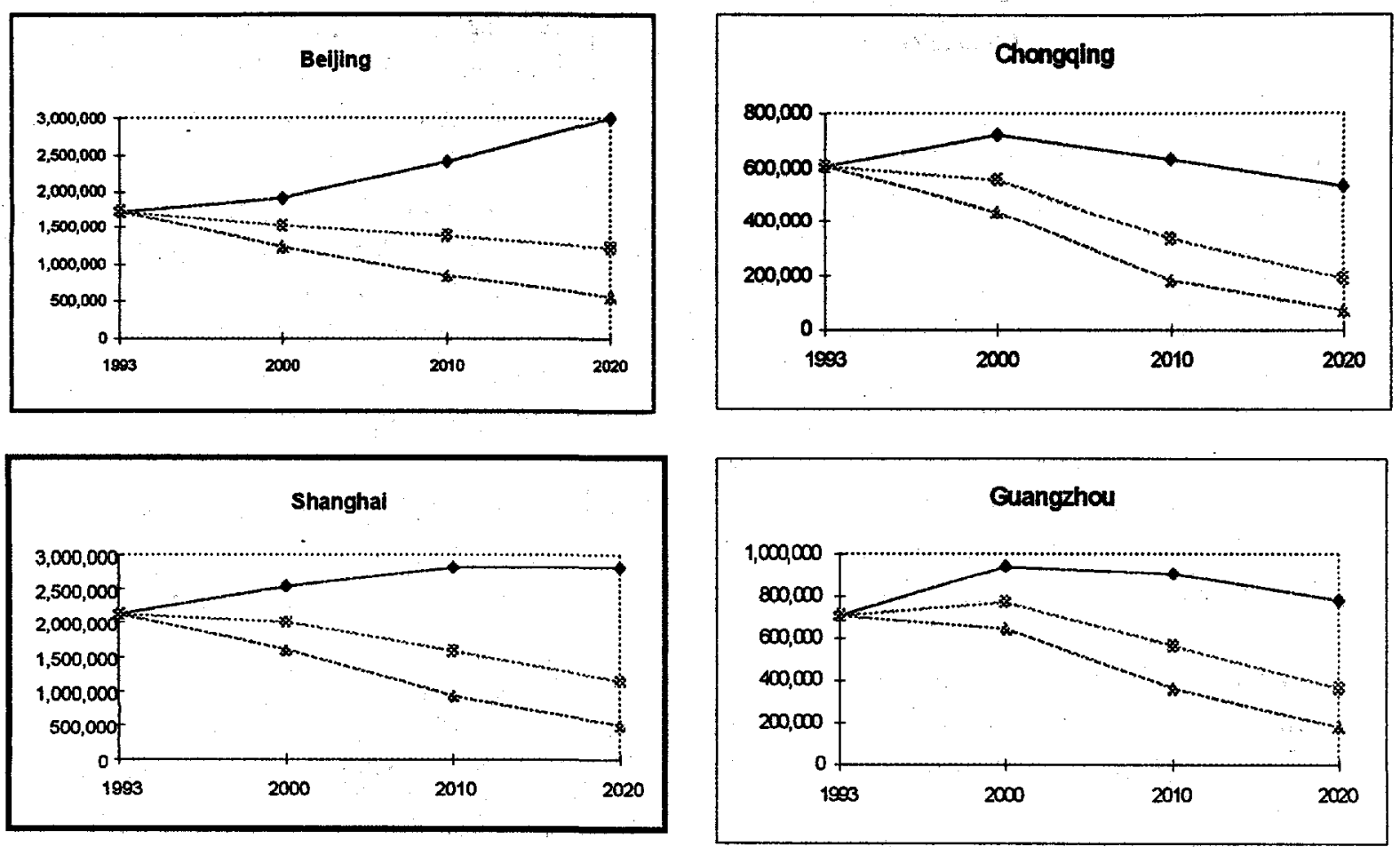

The full results of strengthened regulation are portrayed in Figure 26. To produce these estimates, we have calculated the cumulative projected annual deaths from 1997 to 2020 in the three scenarios. Net lives saved in the two increased-levy scenarios are calculated by subtracting cumulative deaths from cumulative deaths in the pure reform case. The lifesaving value of the levy emerges clearly in this illustration. Beijing, for example, saves about 14,000 lives with a $5 \%$ annual increase and 24,000 lives with a $10 \%$ increase. Chongqing saves 9,000 and 16,000 lives, respectively, and

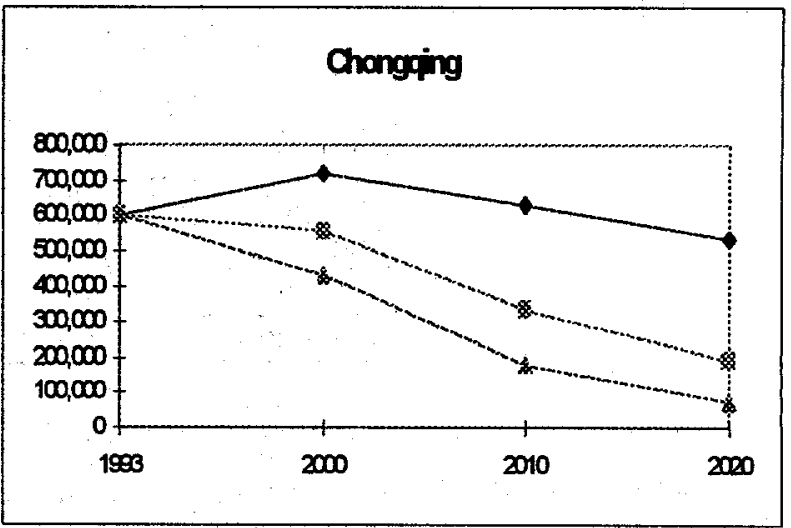

Figure 25c: Industrial TSP Emissions in Three Scenarios lifesaving in the other cities is also counted in the thousands. 
Finally, we should note that pollution-related deaths remain at high levels even in the strict regulation scenario. Figure 27 displays the prospects. Faced with industrial output increases in the range of $150-300 \%$ during the next two decades, our focal cities face very heavy loss of life even with greatly-increased regulation of pollution. The cases of Beijing and Chongqing are particularly grim, with total deaths above 70,000 in the pure reform scenarios and dropping into the range 50,00060,000 with the $10 \%$ annual levy increase.

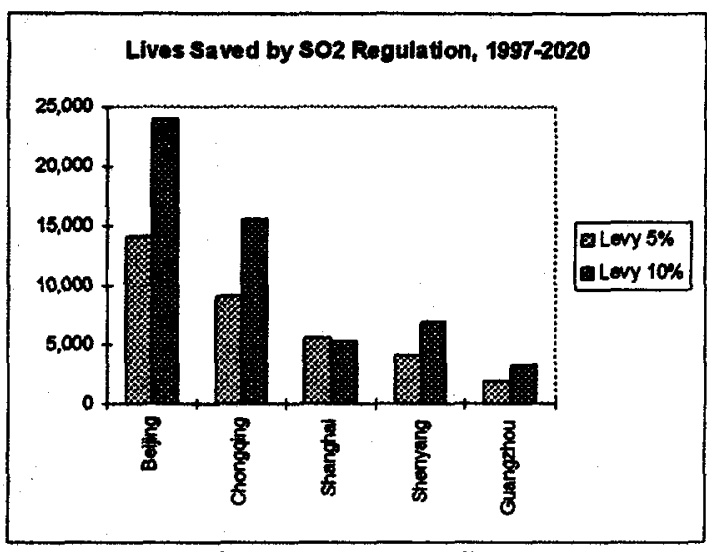

Figure 26: Lifesaving in Two Scenarios Chongqing loses over 50,000 people in all the scenarios; Shenyang and Shanghai over 10,000.

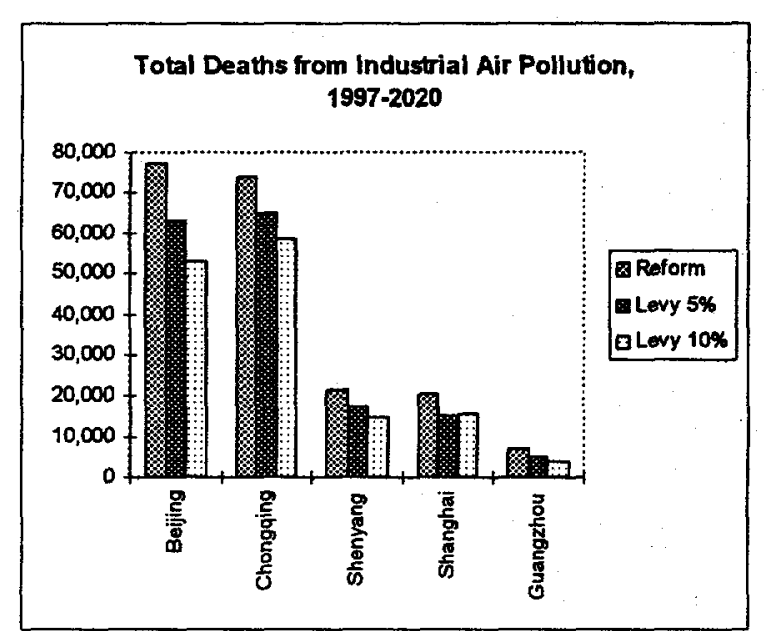

Figure 27: Cumulative Deaths from Air

Pollution, 1997 - 2020
In view of these projected losses, it is appropriate to pose the question: Can further abatement possibly be too costly to justify the loss of so many lives? This seems hard to believe on the face of it, since many Chinese cities are moving toward decent public health standards in other domains. In the next section, we turn to the assessment of benefits and costs: How much air pollution in China's urban centers would it be socially worthwhile to abate?

\section{Is Stricter Regulation Worthwhile?}

Certainly, lifesaving through air pollution reduction is a laudable objective. However, China remains a poor country with many basic needs unmet for hundreds of millions of citizens. Public investment in health facilities and education can also yield major health benefits, and direct investment in productive capital can improve health by increasing incomes. An appropriate welfare analysis of air pollution abatement must therefore consider its costs, as well as its benefits.

Our econometric results show that the cost of abating China's industrial pollution rises steadily at the margin with degree of abatement. At some level of abatement, further pollution reduction may no longer be warranted because the same resources could be used for other investments with greater lifesaving potential. Using two cases to illustrate our 
approach, we address this issue with a systematic assessment of abatement benefits and costs.

\subsection{Case 1: Beijing}

\section{Abatement Benefits}

Beijing had a population of about $11,120,000$ in 1993; the mortality rate was about $0.611 \%$; total deaths were about 68,000; and total SO2 emissions were about 366 thousand tons (of which 204 were from industry). From this base, a decrease of 1,000 tons in SO2 emissions decreases total emissions by $(1 / 366 * 100) \%$. Our econometric results imply an associated decrease of $(.51 * 1 / 366 * 100) \%$ in Beijing's ambient SO2 concentration. Applying the Beijing dose-response result of $\mathrm{Xu}$, et. al. (1994) to the new concentration, we obtain an estimated saving of 10.4 lives per year. Dividing both elements by 10 yields a useful round number for policy discussion: 1 life saved per 100 tons abated annually. This is actually a very conservative estimate of potential abatement benefits, since it ignores the likelihood that abating SO2 has significantly lower lifesaving impact per ton than direct abatement of fine particulates (including, of course, those in the sulfates associated with $\mathrm{SO} 2$ emissions).

How should lifesaving be valued for comparison with abatement costs? A useful benchmark is provided by the average wage of a worker in Beijing, which is approximately $\$ 800$ (6526 yuan) per year. A baseline estimate of the loss to society when one worker dies from respiratory disease is the presented discounted value of the annual wage over a working lifetime. For Beijing, this is approximately $\$ 8,000$ in present value terms at a $10 \%$ discount rate. ${ }^{20}$ We should stress that it is a very partial index of loss, for two main reasons. First, it takes no account of pain and suffering. Secondly, it focuses exclusively on mortality, although very large losses are also associated with working days lost to nonfatal respiratory disease. It is a tiny figure when compared with statistical life values commonly employed in the OECD countries. ${ }^{21}$

\footnotetext{
${ }^{20}$ This estimate implicitly assumes that the actual discount rate in China is higher, and that the increment is equal to the expected growth rate in real wages for a currently-employed worker.

${ }^{21}$ For comparison, it is not uncommon to see public policy decisions in the U.S. reflect 'statistical life' values of several million dollars.
} 


\section{Abatement Costs}

Figure 20 illustrates the extreme variation in marginal abatement cost by pollutant, sector, size class, ownership and degree of abatement. It clearly makes little sense to talk about abatement costs in a general way. The interesting question for Chinese regulators is: Which facilities should be regulated, and how much abatement is socially desirable?

28(a)

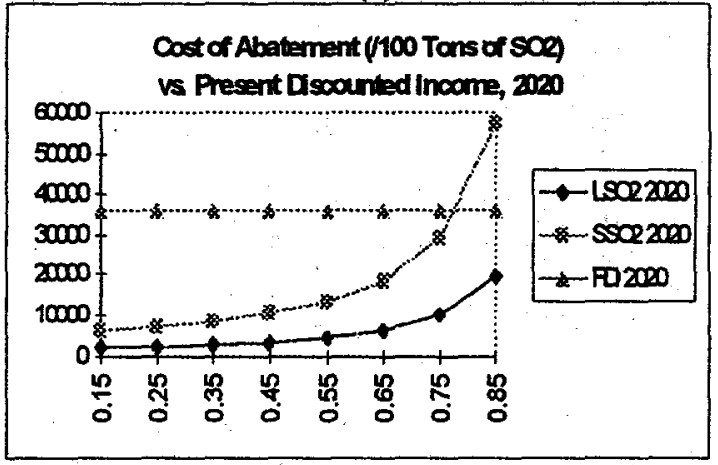

28(b)

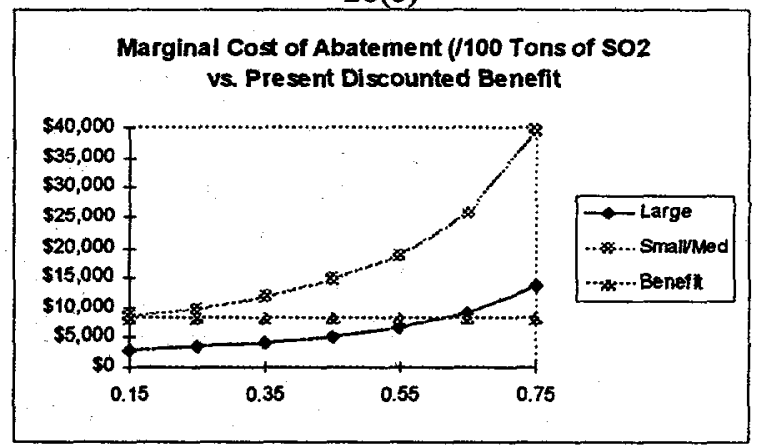

Figure 28: Incremental Benefits and Costs of Air Pollution Abatement

To reflect the overlap between TSP and SO2 as sources of fine particulates, we provide abatement cost evidence for both pollutants in Figure 28. The marginal abatement cost (MAC) schedules are estimated for Beijing by combining our econometric MAC equation with current sectoral and ownership information for that city. Large plants are a major source of air pollution in Beijing, so the MAC numbers for large facilities are particularly interesting. We begin with the more expensive option, $\mathrm{SO} 2$ abatement. Our results show that the MAC curve for 100 tons of SO2 abatement by large plants in Beijing varies from about $\$ 2,900$ at $15 \%$ abatement to $\$ 27,000$ at $85 \%$. ${ }^{22}$ In Figure $28(\mathrm{a})$, the MAC curve for large plants crosses the $\$ 8,000$ incremental benefit line at around $60 \%$ abatement; by implication, the MAC curve for non-SOE large plants would cross the incremental benefit line at a much higher abatement level. The MAC schedule for small facilities crosses the incremental benefit line at around $15 \%$ abatement.

For particulates, the numbers are much more attractive: MAC scarcely rises above $\$ 500$ for 100 tons abated, even at $85 \%$ abatement for small plants. Costs are substantially less for large facilities. MAC estimates for our other four cities differ somewhat, but have the same order of magnitude. A useful contrast is provided by NEPA's current estimates of actual abatement in the five cities, displayed in Table 5.2

\footnotetext{
${ }^{22}$ We should note that this MAC curve is an average which reflects the distribution of production between SOE and non-SOE plants in Beijing. As we have seen, the MAC schedule for non-SOE plants is always far lower than the SOE schedule. A targeted regulatory strategy could, of course, exploit this difference to capture the largest returns from stricter enforcement for the least-cost plants.
} 
According to NEPA, Beijing's current abatement rate for industrial SO2 is $2.5 \%$. For a conservative benefit-cost assessment, we adopt the lowest rate of abatement -- $15 \%$-which has been included in Figure 28 . At $15 \%$ abatement, we estimate the incremental cost of 100 tons of $\$ O 2$ abatement to be $\$ 2,860$. Taking this to be the incremental cost of saving a life, we use our estimated incremental lifesaving benefit $(\$ 8,000)$ to calculate a social rate of return to abatement of approximately $180 \%$.

Table 5.2: Industrial SO2 Abatement in Five Cities

\begin{tabular}{|l|r|r|r|}
\hline & \multicolumn{1}{|c|}{$\begin{array}{c}\text { SO2 } \\
\text { Produced }\end{array}$} & $\begin{array}{c}\text { SO2 } \\
\text { Emitted }\end{array}$ & $\begin{array}{c}\text { Abatement } \\
\%\end{array}$ \\
\hline Shenyang & 196,100 & 144,700 & 26.2 \\
\hline Shanghai & 393,700 & 356,700 & 9.4 \\
\hline Chongqing & 544,800 & 494,800 & 9.2 \\
\hline Guangzhou & 165,100 & 151,500 & 8.2 \\
\hline Beijing & 208,900 & 203,700 & 2.5 \\
\hline
\end{tabular}

We should stress that this estimated rate of return, while clearly attractive, is extremely conservative as a guide to the lifesaving value of air pollution abatement in Beijing. For a large, non-SOE plant, our econometric results imply a MAC of $\$ 332$ for 100 tons of SO2 abated when the abatement rate is $10 \%$. The equivalent figure for 100 tons of particulates abated is around $\$ 120$. If (as seems likely, given overall abatement rate of $2.5 \%$ ) there are large non-SOE plants in Beijing which are abating at less than $10 \%$, then failure to enforce greater abatement is equivalent to valuing a Beijing worker's life at less than $\mathbf{\$ 5 0 0}$. Continued inaction means ignoring a public investment with whose social rate of return is likely to be in excess of $3,000 \%$ ! We believe that the opportunities for such high returns may be quite rare in China's urban health sector.

We conclude that it would make extremely good economic sense to tighten air pollution control in Beijing. Our abatement cost estimates show that it would also be sensible to focus on particulate emissions from large facilities.

\subsection{Case 2: Zhengzhou}

Our results for Beijing do not necessarily yield appropriate conclusions for other urban areas in China. In the first place, our cost analysis reflects only microeconometric evidence on marginal abatement costs (MAC) for end-of-pipe treatment. These almost certainly overstate overall MAC, because process changes often provide the least-cost abatement opportunities for industrial facilities. Secondly, Beijing is not a representative Chinese city for environmental analysis. It is extremely large, and considerably more polluted than the average large urban area in China.

Our second case is designed to address both of these problems. For the abatement cost analysis, we use our cross-provincial econometric results on pollution intensities because they incorporate all abatement options available to Chinese factories. Our focal city is 
Zhengzhou, the capital of Henan Province, which we have chosen because its population, income and air pollution level are representative for China's large cities. ${ }^{23} \mathrm{Zhengzhou's}$ industry pours approximately 45,000 tons of $\mathrm{SO} 2$ into the atmosphere every year, contributing to an ambient $\mathrm{SO} 2$ concentration of $90 \mathrm{ug} / \mathrm{m}^{3}$. At this level of air pollution, Xu's dose-response function predicts that over 400 people are dying annually from SO2related pollution. Thousands more are undoubtedly suffering from serious respiratory illness.

Because Zhengzhou is a representative large city, we use it to develop an estimate of the optimum air pollution levy for urban China. The optimum levy should be set at the point where the incremental benefit of abatement is equal to its incremental cost. To identify this point, we simulate pollution control alternatives by reducing Zhengzhou's $\mathrm{SO} 2$ emissions in $10 \%$ increments until $90 \%$ abatement is reached. We follow the method used for Beijing to estimate reductions in atmospheric $\mathrm{SO} 2$ concentration and mortality from respiratory disease. We value mortality reductions at $\$ 8,000$ per 'statistical life,' yielding the marginal benefit (MB) schedule in Figure 29.

To estimate the marginal cost (MC) schedule, we turn to our cross-provincial econometric results for the SO2-intensity of industrial production. The levy response elasticity in this equation (which is always estimated with the appropriate sign and high statistical significance) registers the overall result when enterprise managers weigh incremental levy payments for pollution against the incremental cost of abatement. At the equilibrium level of pollution intensity, the effective levy rate should be just equal to the incremental cost of abatement for industry as a whole, whether the abatement is achieved by process change or installation of end-of-pipe treatment. Solving the estimated $\mathrm{SO} 2$ intensity equation 'in reverse' for the effective levy rate (or, in equilibrium, the incremental cost of abatement), we obtain an expression for incremental abatement cost as a function of industrial $\mathrm{SO} 2$ intensity. We have plotted this MAC schedule in Figure 29.

${ }^{23}$ Zhengzhou's 1993 population was 1.8 million; it average industrial wage was 3,350 RMB/year. 


\section{The Optimum Air Pollution Levy in Zhengzhou}

Our results for Zhengzhou suggest that air pollution control in Zhengzhou should be far stricter. At the city's current atmospheric SO2 concentration, abating a ton of $\mathrm{SO} 2$ will save about $.63 \%$ of a 'statistical life,' yielding a benefit of approximately $\$ 50$. By contrast, we estimate the incremental cost of abating one ton at the current emissions level (represented by the zero point in Figure 29) to be approximately $\$ 1.70$. Clearly, there is huge social 'profit' to be made by abating more

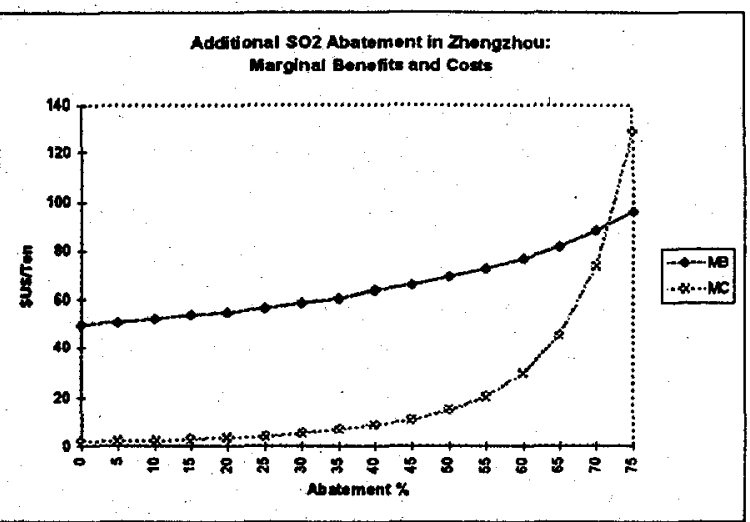

Figure 29: The Optimum Air Pollution Levy in Zhengzhou pollution. As the graph shows, additional abatement remains socially profitable at the margin until about $73 \%$ of current emissions are eliminated. The levy which will induce this reduction is about $\$ 90 /$ ton, at the intersection of the marginal benefit and cost curves. This is our estimate of the optimum industrial air pollution levy for Zhengzhou, since a lower levy would leave socially profitable abatement opportunities unexploited, and a higher levy would impose an abatement cost higher than the social gain from further pollution reduction.

\section{Implications for China}

According to our results, the current levy in Zhengzhou makes sense only if China's policymakers value the life of an average urban resident at approximately $\$ 270$

(\$1.70/.00625). This figure seems tragically low when compared to the loss of a life, with the associated pain, suffering, and elimination of a lifetime's contribution to China's economic output. Even our suggested statistical life value, $\$ 8,000$, is a very conservative number which only takes account of economic output foregone. But to meet even this conservative standard, our result suggests that the air pollution levy should be increased more than fiftyfold in Zhengzhou - and, by implication, in the rest of urban China. The optimum rate -- $\$ 90 /$ ton -- is not exceptionally high by industrial-economy standards (e.g., \$130/ton for tradable SO2 permits in the US (1995); an emissions charge of \$72/ton in Poland (1993), and \$29/ton in France (1992)). However, China is much poorer than any of these countries. The optimal levy for Zhengzhou (and, by implication, for the rest of urban China) is so high because current air pollution is so bad - arguably the worst in the world

\section{Revenue Implications}

The purpose of the levy is to reduce pollution, but it generates public revenue as well. If Zhengzhou's environmental regulators increased the air pollution levy to $\$ 90 /$ ton, the city's annual revenue from air pollution charges would be approximately $\$ 1.1$ million 
( $\$ 90 /$ ton $\times 12,500$ tons after the $73 \%$ reduction). For all of China's large cities, scaling up the Zhengzhou result for a charge of $\$ 90 /$ ton yields a revenue estimate of approximately $\$ 250$ million - a substantial sum, but only a small fraction of the levy's value as a lifesaving policy tool.

\section{Keys to The Future}

Our analysis suggests that well-designed policies can substantially improve China's urban environment, and that the associated costs are well worth incurring. We can summarize the keys to effective policy in the following propositions:

- Continued economic reform is necessary to preserve past environmental gains.

Our research has demonstrated the powerful impact of the reforms on the air and water pollution intensity of Chinese industry. Reform-induced changes in sectoral composition, ownership and scale of production have been sufficient to compensate for much of the increase in scale of output during the past decade. Our projections show that continuation of the reforms can have similar mitigating effects during the coming decades. Rapid industrial growth without further changes in ownership and production scale would produce far greater pollution loads than those contemplated in this study.

- Pollution levy reform would be a very cost-effective investment in public health.

In this paper, we focus on the consequences of strengthening the pollution levy system. Our results suggest that a much higher air pollution levy would save lives very cost-effectively in urban China. However, we would also recommend certain changes in the design of the levy system. Water pollution levies are assessed only on 'abovestandard' discharges, making emissions 'free' for polluters until the standards are reached. The air pollution levy is assessed on the total volume of air pollutants, but it is not fully adjusted for individual pollutants according to relative risk. For both air and water emissions, it would be sensible to consider adoption of a complete charge system which would be targeted on specific pollutants and assessed on all units of pollution. Recent research on the water pollution levy (Dasgupta, Huq, Wheeler and Zhang, 1996) has demonstrated that a revised system could be considerably more costeffective.

- Enforcement should be targeted on low-cost sources.

The cost analysis in this paper shows why targeting is a good idea: Large polluters are easier to monitor, and have far lower unit abatement costs. The key to cost-effective reduction of industrial pollution in China's cities is targeted enforcement of higher abatement standards for large facilities. 
- Township-Village Industrial Enterprises (TVIE's) should be fully integrated into the regulatory system.

Our results show that stronger regulation has produced significant reduction of industrial pollution in China. However, many TVIE's remain outside the current sphere of regulation. Pollution from T.VIE's is a 'dark star' on China's horizon: It is growing rapidly, but currently-available information is insufficient to judge the consequences. Inclusion of major TVIE pollution sources should be a priority for China's regulators during the coming decade.

- Rapid development will promote stricter pollution control.

In the long run, this may be the most important factor of all. Recent research has shown that the strength of regulation in China's provinces is heavily affected by their levels of social and economic development. Poor communities with low education levels are far less able to promote their environmental interests than their more highlydeveloped counterparts. Ultimately, China's environmental interests will be best served by rapid economic development, coupled with concerted efforts to inform and empower poorer communities.

\section{Conclusions}

China's industrial growth in the era of reform is a remarkable success story, but it has been clouded by serious pollution damage. Hundreds of thousands of people are suffering premature death or serious respiratory illness from exposure to industrial air pollution. Many of China's waterways are seriously contaminated by industrial discharges, rendering them largely unfit for direct human use. However, China's own experience during the past decade shows that this damage can be substantially reduced at modest cost. Much potential damage has been avoided already, through the impact of China's economic reform policies on industry, and the specific effect of stricter regulation in some polluted areas. Together, these policies have lowered industry's pollution intensity sufficiently to reduce organic water pollution in many areas, and to curb the growth of air pollution in the face of rapid industrial growth.

Despite this encouraging progress, a conservative assessment of the benefits and costs of further air pollution abatement suggests that much higher levels of particulate and $\mathrm{SO}_{2}$ emissions control are warranted in China's polluted cities. For our analysis, we have developed three scenarios which project pollution damage under varying assumptions about future policies. Even if regulation is not tightened further, we find that continued economic reform should have a powerful effect on pollution intensity. Organic water pollution will stabilize in many areas, and actually decline in some. Air pollution will continue growing in most areas, but at a much slower pace than industrial output. 
However, our projections also highlight the unnecessarily high cost of regulatory inaction. If economic reform is not supplemented by tighter regulation, most of China's waterways will remain heavily polluted and many thousands of people will die or suffer serious respiratory damage from air pollution. Continuing recent trends in tightened regulation for water pollution will result in sharp improvements; adopting an economically-feasible policy of much stricter regulation will restore the health of many waterways. In the case of air pollution, the stakes are even higher because regulatory enforcement has apparently weakened in many areas during the past half-decade. Reversal of this trend will save many lives at extremely modest cost. Adoption of NEPA's recent recommendation for a tenfold increase in the air pollution levy would produce a major turnaround in most cities, and our results suggest that even NEPA's recommendation is very conservative. For a representative Chinese city, Zhengzhou, we find that a fiftyfold increase in the levy appears warranted from an economic perspective.

Finally, our microeconomic analysis of abatement alternatives has highlighted the costeffectiveness of a pollution control policy targeted on large sources of particulate and SO2 emissions. Abatement of particulates from large non-SOE plants is so cheap that even an extremely conservative economic analysis affirms the benefits of very high abatement levels. Our analysis suggests that high social rates of return can be obtained from regulation which induces at least $70 \%$ abatement of $\mathrm{SO} 2$ and even greater abatement of particulates from large urban industrial facilities. At present, lax regulation of such facilities is causing so much health damage that reform seems imperative. Inaction amounts to valuing a Chinese worker's life at less than \$US 500, a figure which is tragically low by any standard. 


\section{References}

Afsah, Shakeb, Benoit Laplante and David Wheeler, "Controlling Industrial Pollution: A New Paradigm," 1996, World Bank, Policy Research Department Working Paper, November

Dasgupta, Susmita, Mainul Huq, David Wheeler and C.H. Zhang, 1996, "Water Pollution Abatement by Chinese Industry: Cost Estimates and Policy Implications," World Bank Policy Research Department Working Paper No. 1630, August

Dasgupta, Susmita and David Wheeler, "Citizen Complaints as Environmental Indicators: Evidence from China," 1996, World Bank Policy Research Department Working Paper, December

Dasgupta, Susmita, Mainul Huq and David Wheeler, "Bending the Rules: Determinants of Discretionary Pollution Control in China," 1997, World Bank Policy Research Department Working Paper, January

Hartman, Raymond, Mainul Huq and David Wheeler, 1996, "Why Paper Mills Clean Up: Survey Evidence From Four Asian Countries," World Bank Policy Research Department Working Paper, December

Hettige, Mala, Paul Martin, Manjula Singh and David Wheeler, 1995, "IPPS: The Industrial Pollution Projection System," World Bank Policy Research Department Working Paper, February

Hettige, Mala, Mainul Huq, Sheoli Pargal and David Wheeler, 1996, "Determinants of Pollution Abatement in Developing Countries: Evidence from South and Southeast Asia," World Development, December

Mani, Muthukumara and David Wheeler, 1997, "In Search of Pollution Havens? Dirty Industry in the World Economy, 1960-1995," World Bank Policy Research Department Working Paper (forthcoming)

Martin, Paul, Mainul Huq and David Wheeler, "Process Change, Economic Policy, and Industrial Pollution: Cross Country Evidence from the Wood Pulp and Steel Industries," paper presented at the Annual Meetings, American Economic Association, Anaheim, California, January 1993

Lucas, Robert, 1996, "Environmental Regulation and the Location of Polluting Industry in China," World Bank, Policy Research Dept. (mimeo.)

Pargal, Sheoli and David Wheeler, 1996, "Informal Regulation of Industrial Pollution in Developing Countries: Evidence from Indonesia," Journal of Political Economy, December 
Xu, Xiping, J. Gao, D. Dockery and Y. Chen, 1994, "Air Polluxion and Daily Mortality in Residential Areas of Beijing, China," Archives of Environmental Health, 49(4), 216-22

Xu, Z.Y., X. Xu, C.H. Chen, T. Kjellstrom, et. al., 1995, "Air Pollution and Daily Mortality in Shenyang" (mimeo.)

Wang, Hua and David Wheeler, 1996, "Pricing Industrial Pollution in China: An Econometric Analysis of the Levy System," World Bank Policy Research Department Working Paper No. 1644, September

Wheeler, David, 1991, "The Economics of Industrial Pollution Control: An International Perspective," World Bank Industry and Energy Department Working Paper No. 60, January 


\section{Appendix}

This Appendix describes the econometric equations which have been used for the simulations in the paper. Most of our information has been made available by NEPA and the Tianjin Environmental Protection Bureau, either as databases from the agencies' internal files or, in the case of NEPA, in published Environmental Yearbooks. Some additional information has been drawn from the National Industrial Yearbooks.

\section{A.1 Regulation of Industrial Water Pollution ${ }^{1}$}

Our COD intensity equation is based on an analysis of the regulatory experience of 29 Chinese provinces during the period 1987-93. For this analysis, we used a structural model to investigate the sources of covariation in water pollution intensity (provincial COD emissions/output) and the effective water pollution levy rate (actual collections per unit of above-standard wastewater discharge).

Our estimation exercise was based on a model of 'equilibrium pollution': In each region and period, the effective levy rate (or 'price of pollution') and pollutant discharge are jointly determined by the intersection of environmental demand (ED) and supply (ES) functions. The ED function relates industrial pollution intensity to the local price of pollution. It reflects the economics of cost-minimizing abatement by industry, and is formally equivalent to the marginal abatement cost (MAC) function in textbooks of environmental economics. The ES function specifies the pollution price imposed by the community as damage rises. While it reflects considerations of marginal social damage (MSD), ES is not equivalent to the textbook MSD function because it reflects the interplay of limited information, perceived self-interest, and differential ability or willingness to enforce community standards. Equilibrium pollution (at the intersection of ED and ES) is therefore not necessarily optimal pollution (at the intersection of ED and MSD).

In modeling environmental supply, we focused particularly on the role of endogenous enforcement. Across provinces, regulators may differ greatly in their ability or willingness to enforce the formal regulations. In practice, regulation is almost never a 'pure' administrative process in which violations are unambiguously observed and rules are uniformly enforced. Because industry is a prime generator of income and employment, regulatory enforcement is often subjected to political pressure for leniency. ${ }^{2}$ Even when they are unencumbered, regulators are generally reluctant to impose penalties which will bankrupt or shut down factories. They may, however, be tougher in relatively affluent regions where communities put more stress on environmental quality.

Environmental demand reflects the price of pollution, but it also may be affected by plant, firm and industry characteristics. We used output shares by sector to control for sectoral differences in pollution intensity. The estimated effect of provincial differences in sector

${ }^{1}$ For a more detailed discussion, see Wang and Wheeler (1996).

2 See Wheeler (1991). 
shares will depend on the degree to which sectoral regulatory standards adjust for differences in sectoral wastewater intensities, influent intensities and abatement costs. If there is full adjustment (i.e., proportionately lower standards for wastewater- and influentintensive sectors with high abatement costs; higher standards for the opposite case), sectoral shares will have no independent effect.

Plant size is another potentially-important determinant of pollution intensity. However, while abatement scale economies are clearly present at the plant level, they do not affect province-level aggregates. Therefore, we could not use provincial industrial output to capture scale effects. However, the available data do distinguish between production from small, medium and large industrial facilities. We therefore controlled for this factor by introducing the share of provincial output produced by large plants.

We also controlled for state ownership, since several considerations suggest that stateowned plants may be more pollution intensive than other facilities. First, state-owned factories may simply generate more waste residuals per unit of output because they are less efficient. Secondly, soft budget constraints may make them less sensitive to pollution levies. Finally, evidence from other Asian countries suggests that state-owned factories resist regulation more successfully than privately-owned plants (Pargal and Wheeler, 1996; Hettige, Huq, Pargal and Wheeler (1996), Hartman, Huq and Wheeler, 1996). We controlled for this factor by introducing the provincial share of production in state-owned factories.

After these adjustments, the estimation equation for the cross-provincial data set is as follows (for the rth province):

$$
\log C O D I_{r}=\alpha_{0}+\sum_{j=1}^{N} \alpha_{1 k} s_{k_{r}}+\alpha_{L} L A R G E_{r}+\alpha_{G} S T A T E_{r}+\alpha_{p} \log P L W_{r}+\varepsilon_{r}
$$

Prior expectations: $\alpha_{L}<0, \alpha_{G}>0, \alpha_{p}<0$

where

$$
\begin{array}{ll}
\text { CODI } & =\text { COD intensity (COD discharge / Industrial output) } \\
\text { S }_{\mathbf{k r}} & =\text { The industrial output share of the kth sector } \\
\text { LARGE }_{\mathbf{r}} & =\text { The industrial output share of large plants } \\
\text { STATE }_{\mathrm{r}} & =\text { The industrial output share of state-owned plants } \\
\text { PLW }_{\mathbf{r}} & =\text { Effective pollution levy per unit of excess wastewater discharge } \\
\varepsilon_{\mathrm{r}} & =\text { A stochastic error term incorporating provincial components }
\end{array}
$$

On the supply side, we have measures for the relevant variables at the provincial level. The appropriate estimating equation is therefore specified as follows: 
$\log P L W_{r}=\log P O P D_{r}+\log \left(\omega_{1} \omega_{0}\right)+\left(\omega_{1}-1\right) \log C O D D_{r}+\omega_{2} \log I N C_{r}$

$+\omega_{3} \log I N D_{r}+v_{r}$

Prior expectations: $\omega_{1}>1\left(\omega_{1}-1>0\right), \omega_{2}>0, \omega_{3}>0$

where

$$
\begin{array}{ll}
\mathrm{PLW}_{\mathrm{r}} & =\text { Effective pollution levy per unit of excess wastewater discharge } \\
\mathrm{CODD}_{\mathrm{r}} & =\text { COD emissions per unit of provincial land area (or pollution density) } \\
\mathrm{POPD}_{\mathrm{r}} & =\text { Provincial population density } \\
\mathrm{INC}_{\mathrm{r}} & =\text { Provincial income per capita } \\
\mathrm{IND}_{\mathrm{r}} & =\text { Industry share of provincial output (a proxy for local bargaining } \\
& \text { power) } \\
v_{\mathrm{r}} & =\text { A stochastic error term incorporating provincial components }
\end{array}
$$

In equations (1.1 - 1.2), PLW and CODI are jointly determined. In addition, the error terms in both equations are likely to incorporate provincial fixed effects. We have therefore estimated the two equations using two-stage least squares and the appropriate error components model. The use of fixed-effects also permitted us to control for institutional and historical factors which may affect industrial pollution intensities and regulatory enforcement practices across China's provinces.

Our results for COD intensity are reported in Table A.1a. The elasticity of COD intensity with respect to the effective water pollution levy is quite high (-.8); state-owned enterprises have significantly higher COD intensities, while large plants have lower ones. After these factors are accounted for, a few sectors have exceptionally high or low COD intensities. COD intensity in the power sector is significantly lower than average, while higher-than-average intensities characterize metals, coal mining, building material mining, chemical fiber production and transportation equipment manufacturing.

The results for the effective water pollution levy are reported in Table A. 1b. Collinearity is clearly a problem, but the results suggest that pollution load, exposed population and provincial development level all affect the 'price of pollution.' 
Table A.1: COD Intensity and the Effective Water Pollution Levy

(a) COD Intensity Equation

\begin{tabular}{|l|r|}
\hline \multicolumn{2}{|c|}{ Dependent Variable: Log COD Intensity } \\
\hline Independent Variable & $\begin{array}{l}\text { Coefficients } \\
\text { (t-ratio) }\end{array}$ \\
\hline Log Effective Levy & $\begin{array}{r}-0.835 \\
(-3.785)\end{array}$ \\
\hline State Enterprise Share & 1.832 \\
& $(2.726)$ \\
\hline Large Plant Share & -3.921 \\
& $(-5.600)$ \\
\hline Sector Shares & 6.673 \\
\hline Metal Products & $(2.022)$ \\
\hline Power & -10.705 \\
& $(-2.905)$ \\
\hline Coal Mining & 10.899 \\
& $(2.527)$ \\
\hline Building Material Mining & 12.109 \\
& $(2.383)$ \\
\hline Chemical Fibers & 9.763 \\
& $(2.472)$ \\
\hline Transport Equipment & 4.834 \\
& $(2.187)$ \\
\hline Adjusted R2 & 0.819 \\
\hline
\end{tabular}

(b) Effective Water Pollution Levy Equation

\begin{tabular}{|l|r|}
\hline $\begin{array}{l}\text { Dependent Variable: Log (Effective COD } \\
\text { Levy) }\end{array}$ \\
\hline Independent Variable & $\begin{array}{l}\text { Coefficients } \\
\text { (t-ratio) }\end{array}$ \\
\hline Log COD Density & 0.127 \\
& $(1.342)$ \\
\hline Log Pop. Density & 2.44 \\
& $(2.630)$ \\
\hline Log Income Per Capita & 0.342 \\
& $(1.259)$ \\
\hline Log Industry Share & 0.242 \\
& $(0.863)$ \\
\hline & \\
\hline Adjusted R2 & 0.794 \\
\hline
\end{tabular}




\section{A.2 Regulation of Industrial Air Pollution}

As noted in the paper, our results for the effective air pollution levy are different from those for water in one important respect: We find no evidence that the air levy is jointly determined with industrial air pollution intensity; nor do we find any evidence that measures of exposed population or provincial development have a significant impact on the levy. We therefore report only the air pollution intensity equations which have been used for the simulation work in this paper.

The estimation equation for the cross-provincial data set is as follows (for the rth province):

$$
\log A I R I_{r}=\alpha_{0}+\sum_{j=1}^{N} \alpha_{1 k} s_{k_{r}}+\alpha_{L} L A R G E_{r}+\alpha_{G} S T A T E_{r}+\alpha_{p} \log P L W_{r}+\varepsilon_{r}
$$

Prior expectations: $\alpha_{L}<0, \alpha_{G}>0, \alpha_{p}<0$

where

$$
\begin{array}{ll}
\text { AIRI } & =\text { Air pollution intensity (discharge / industrial output) } \\
\mathrm{s}_{\mathrm{kr}} & =\text { The industrial output share of the kth sector } \\
\text { LARGE }_{\mathrm{r}} & =\text { The industrial output share of large plants } \\
\text { STATE }_{\mathrm{r}} & =\text { The industrial output share of state-owned plants } \\
\text { PLA }_{\mathrm{r}} & =\text { Effective air pollution levy per unit of pollutant discharge } \\
\varepsilon_{\mathrm{r}} & =\text { A stochastic error term incorporating provincial components }
\end{array}
$$

As in the case of water pollution, the use of provincial fixed-effects has permitted us to control for institutional and historical factors which may affect air pollution intensities across China's provinces. Results are reported in Table A.2 (a,b) 
Table A.2: Air Pollution Intensity Equations

Log SO2 Intensity

Variables
Log Effective Levy
State Enterprise Share
Log Large Plant Share
Non-Ferrous Metals
Ferrous Metals Mining
Petroleum and Nat.
Gas Extraction
Education, Sports
Products

Adjusted R2
Coefficients (t-ratios)

$-0.321$

$(-1.528)$

1.859

(3.374)

$-3.921$

$(-8.083)$
Log Smoke Intensity

Variables

Log Effective Levy

State Enterprise

Share

Large Plant Share

Targe Plant Share

(nentor

\section{Sector Shares}

12.652 Metal Products
(3.592)

7.906

(1.708)

4.001

(1.612)

$-35.559$

$(-2.553)$

Paper

Ferrous Metals

Mining

Education, Sports

Products

Furniture

0.880

Adjusted R2
Coefficients

(t-ratios)

$-0.796$

$(-3.433)$

3.126

(5.094)

$-2.514$

$(-3.538)$
Log Dust Intensity

Variables

Coefficients (t-ratios)

Log Effective Levy

$-0.434$

$(-1.646)$

2.298

$(4.054)$

$-6.458$

$(-6.151)$

The results on air pollution intensity are quite similar, although the estimated elasticities differ across equations. Elasticities of response to the effective air levy are -.3 for $\mathrm{SO} 2$, -.8 for smoke, and -.4 for dust. In all three cases, state enterprises are significantly more pollution intensive and large plants significantly less so. Sectors with unusually large or small pollution intensity differ somewhat across the three equations.

\section{A.3 Determinants of SO2 Concentration Across Chinese Cities}

Simulation of future health impacts requires translating projected air pollutant emissions into atmospheric concentrations. In the case of SO2, we were able to fit an econometric equation to data from major Chinese cities during the period 1991-1993. The results, reported in Table A.3, describe the relationship between total SO2 emissions and atmospheric SO2 concentration, controlling for temperature and precipitation. We find no significant impact for temperature, but the results show that cities with higher precipitation have markedly lower atmospheric SO2 concentrations, controlling for the level of SO2 emissions. The impact of emissions on atmospheric concentration is highly significant in both equations, with an estimated elasticity of .51 . 
Table A.3: SO2 Concentration Equation

\begin{tabular}{|l|r|r|}
\hline \multicolumn{3}{|c|}{ Log SO2 Concentration } \\
\hline Variables & \multicolumn{2}{|c|}{$\begin{array}{c}\text { Coefficients } \\
\text { (t-ratios) }\end{array}$} \\
\hline Log SO2 Density & 0.513 & 0.508 \\
& $(4.866)$ & $(4.976)$ \\
\hline Log Temperature & -0.061 & \\
& $(-0.201)$ & \\
\hline Log Precipitation & -0.325 & -0.352 \\
& $(-1.645)$ & $(-2.481)$ \\
\hline Constant & 4.718 & 4.759 \\
& $(4.866)$ & $(5.068)$ \\
\hline & & \\
\hline Adjusted R2 & 0.290 & 0.302 \\
\hline
\end{tabular}

\section{A.4 The Cost of Air and Water Pollution Abatement ${ }^{3}$}

Using large plant-level databases provided by NEPA and the Tianjin EPB for 1993, we have analyzed end-of-pipe abatement costs for major air and water pollutants. Our estimation exercise reflects both economic and engineering considerations in abatement. From an economic perspective, industrial facilities can abate pollution by scaling back polluting activities or by diverting resources to cleanup. In either case, pollution reduction will entail costs. Moreover, diminishing returns apply; more resources have to be devoted to cleaning up each additional unit of pollutant. Hence, industry's marginal abatement cost (MAC) function slopes upward from right to left as pollution falls.

The engineering literature identifies four major factors which determine the cost of abatement: Pollutant type, diversity of emission sources, scale of abatement, and pollutant concentration in the waste stream. Generally then, the position and slope of the MAC function are affected by factors such as the scale and sectoral composition of production: the average operating efficiency of the firm; the available process technologies; and the efficiency of waste treatment technologies. For any given level of pollution, more costly pollution control is associated with rightward movement of the MAC function.

Abatement processes frequently reduce more than one air or water pollutant, so joint cost function estimation is appropriate. For example, stack scrubbers remove both Total Suspended Particulates (TSP) and Sulfur dioxide (SO2) from waste gas; Biological Oxygen Demand (BOD), Chemical Oxygen Demand (COD), and Suspended Solids (TSS) can all be removed from waste water in common facilities. These joint equipment requirements are associated with common use of skilled and unskilled labor, energy and materials.

\footnotetext{
${ }^{3}$ For a more detailed discussion, see Dasgupta, Huq and Wheeler (1996).
} 
Assuming that the abatement cost function is separable from the firm's production cost function, reflecting purely end-of-pipe activity, our regression model for joint abatement of $\mathrm{k}$ pollutants is specified as a second-order quadratic approximation to the general cost function (or translog function):

$\ln C_{i}=a_{0}+a_{1} \ln W_{i}+a_{11} \ln W_{i}^{2}+\sum_{j=1}^{N} \beta_{j} \ln \left(\frac{E_{i j}}{I_{i j}}\right)+\sum_{j=1}^{N} \delta_{j} \ln \left(\frac{E_{i j}}{I_{i j}}\right) \ln W_{i}$

$$
+\sum_{j=1}^{N} \sum_{k=1}^{N} \gamma_{i j} \ln \left(\frac{E_{i j}}{I_{i j}}\right) \ln \left(\frac{E_{i k}}{I_{i k}}\right)+\beta_{\mathrm{jj}}\left[\ln \left(\frac{E_{i j}}{I_{i j}}\right)\right]^{2}+\sum_{m=1}^{M} \phi_{m} X_{i m}+\varepsilon_{i}
$$

where

$\mathrm{C}_{\mathrm{i}}$ : Total annual cost of end-of-pipe abatement for the plant $\mathrm{i}$

$\mathrm{W}_{\mathrm{i}}$ : Total annual wastewater or waste gas volume

$E_{j} / I_{j}$ : Vector of effluent/influent ratios for $n$ pollutants, which can be interpreted either as concentration ratios or volume ratios (since waste water or gas volume is constant across influent and effluent for each plant, it cancels out of the concentration ratio).

$\mathrm{X}_{\mathrm{m}}$ : Vector of relevant plant characteristics (sector, age, ownership)

$\varepsilon_{\mathrm{i}} \quad$ Vector of random disturbances. ${ }^{4}$

Abatement in Equation (1.4) is measured by $\mathrm{E} / \mathrm{I}$, which reflects the percent reduction in the pollutant as it passes from pre-abatement influent concentration I to post-abatement effluent concentration $\mathrm{E}$.

We have estimated (1.4) for four water pollutants (BOD, COD, TSS, and other pollutants); and two air pollutants (TSP, SO2). Our data are from the China Environmental Monitoring Station in Beijing, which monitors the 3000 factories currently rated as China's largest potential polluters. For this exercise China's National Environmental Protection Agency (NEPA) provided us with 1993 data for approximately 1000 factories. ${ }^{5}$

Testing alternative nested specifications of the cost function (1.4), we have found that we cannot reject the restrictions associated with a constant-elasticity (log-log) model for water, and a log-log model with quadratic scale effects for air. In order to control for

${ }^{4}$ An appropriate cost function should include a vector of input prices at the location of plant $i$; but we exclude input prices, since cross-regional price indices are not presently available to us.

${ }^{5}$ These factories are scattered across China's urban/industrial areas. Many facilities have multiple emission sources. The database includes information on treatment, emissions by pollutant, abatement, and abatement costs for each emission source. 
potential simultaneity in the joint determination of emissions and abatement $\operatorname{costs}^{6}$, we have estimated the equations using two-stage least squares. ${ }^{7}$

Regression results are reported in Table A.4. In the regressions, all the key parameters have the expected signs and high levels of statistical significance. The marginal cost of abatement rises significantly with degree of abatement (measured in inverse form by the effluent/influent ratios for pollutants), and marginal cost schedules vary considerably by pollutant. Significant scale economies are observed in both cases (e.g. for water, the elasticity of total cost with respect to scale is 41 : When scale increases by $1 \%$, total cost increases by . $41 \%$ ).

Abatement costs differ significantly by sector. After controlling for scale and degree of abatement, oil refining is relatively high cost and food processing is relatively low cost for water pollution abatement. On the other hand chemicals, oil refining and non-ferrous metals processing are relatively high cost, and cement is relatively low cost, for air pollution abatement.

We have also tested for the impact of plant age and ownership on abatement costs, with mixed results. Neither state ownership nor age has a significant impact on the cost of water abatement. Age is insignificant for air pollution abatement cost as well, but stateowned enterprises do have significantly higher abatement costs after controlling for other factors.

\footnotetext{
${ }^{6}$ Since these two variables are theoretically jointly-determined in the cost minimization exercise of the plant, the abatement parameter estimates of ordinary least squares may be biased.

${ }^{7}$ In the first stage regressions, discharge of each pollutant (the numerator of $E / I$ ) is regressed on total plant employment, treatment scale, influent volume for the pollutant, age of plant, a dummy variable for state ownership, and the relevant sectoral standard, depending on data availability.
} 
Table A.4: Abatement Cost Function Estimation Results

Variable Descriptions:

Water:

LTRTW = Log (Volume of Wastewater Treated)

LTSS $\quad=$ Log (Effluent/Influent) for Total Suspended Solids

LCOD = Log (Effluent/Influent) for Chemical Oxygen Demand

LBOD $=\log$ (Effluent/Influent) for Biological Oxygen Demand

LOTH = Log (Effluent/Influent) for other water pollutants

Air:

LTRTWG $=$ Log (Volume of Waste Gas Treated)

LTSP $=\log$ (Effluent/Influent) for Pollutants other than SO2 (principally TSP)

$\mathrm{LSO}_{2}=\mathrm{Log}($ Effluent/Influent) for SO2

\begin{tabular}{|c|c|c|c|c|c|}
\hline & Water P & llutants & & Air Po & utants \\
\hline & Coefficient & $t$ & & Coefficient & $t$ \\
\hline Intercept & 4.4692 & 22.508 & Intercept & 8.6810 & 3.375 \\
\hline LTRTW & 0.4081 & 27.920 & LTRTG & -0.5528 & -1.808 \\
\hline LTSS & -0.0530 & -2.487 & LTRTG*LTRTG & 0.0269 & 2.960 \\
\hline LCOD & -0.1464 & -4.402 & $\mathrm{LSO}_{2}$ & -0.2642 & -3.925 \\
\hline LBOD & -0.2208 & -3.722 & LTSP & -0.1128 & -3.037 \\
\hline LOTH & -0.1025 & -6.303 & Chemicals & 0.5823 & 2.586 \\
\hline Food & -0.7403 & -4.285 & Cement & -1.5781 & -5.958 \\
\hline Textiles & 0.3202 & 2.377 & Oil Refining & 1.5269 & 3.889 \\
\hline Oil Refining & 1.6723 & 10.032 & $\begin{array}{l}\text { Non-Ferrous } \\
\text { Metals }\end{array}$ & 1.1134 & 3.525 \\
\hline Chemicals & 0.1589 & 1.797 & State-Owned & 1.6509 & 4.030 \\
\hline Adjusted $\mathrm{R}^{2}$ & & 0.32 & Adjusted $\mathrm{R}^{2}$ & & 0.47 \\
\hline $\begin{array}{l}\text { No. of } \\
\text { Observations }\end{array}$ & & 2221 & $\begin{array}{l}\text { No. of } \\
\text { Observations }\end{array}$ & & 284 \\
\hline
\end{tabular}

From the log-log form of equation (1.4), with potential quadratic scale effects, we have derived the following plant-level total and marginal cost equations:

(1.5) $C=e^{\alpha_{0}} W^{\alpha_{1}+\alpha_{2} \log W} \prod_{j=1}^{N}\left[\frac{E_{j}}{I_{j}}\right]^{\beta_{t}}$ 
(1.6) $\frac{\partial C}{\partial E_{k}}=\frac{\beta_{k}}{E_{k}} e^{\alpha_{0}} W^{\alpha_{1}+\alpha_{2} \log W} \prod_{j=1}^{N}\left[\frac{E_{j}}{I_{j}}\right]^{\beta_{1}}$

In the paper, we draw on equation (1.6) to estimate marginal costs of pollution abatement (in annual dollars/ton) by pollutant, for plants of different ownership categories in different sectors and size classes. ${ }^{8}$

${ }^{8}$ Note that $\alpha_{2}=0$ for water abatement. 

Policy Research Working Paper Series

\begin{tabular}{|c|c|c|c|c|}
\hline & Title & Author & Date & $\begin{array}{l}\text { Contact } \\
\text { for paper }\end{array}$ \\
\hline WPS1828 & $\begin{array}{l}\text { The Determinants of Banking Crises: } \\
\text { Evidence from Developed and } \\
\text { Developing Countries }\end{array}$ & $\begin{array}{l}\text { Asli Demirgüç-Kunt } \\
\text { Enrica Detragiache }\end{array}$ & September 1997 & $\begin{array}{l}\text { P. Sintim-Aboagye } \\
38526\end{array}$ \\
\hline WPS1829 & $\begin{array}{l}\text { Economic Reform and progress in } \\
\text { Latin America and the Caribbean }\end{array}$ & $\begin{array}{l}\text { Norman Loayza } \\
\text { Luisa Palacios }\end{array}$ & September 1997 & $\begin{array}{l}\text { E. Khine } \\
37471\end{array}$ \\
\hline WPS1830 & $\begin{array}{l}\text { Private Ownership and Corporate } \\
\text { Performance: Some Lessons from } \\
\text { Transition Economies }\end{array}$ & $\begin{array}{l}\text { Roman Frydman } \\
\text { Cheryl W. Gray } \\
\text { Marek Hessel } \\
\text { Andrzej Rapaczynski }\end{array}$ & September 1997 & $\begin{array}{l}\text { B. Moore } \\
38526\end{array}$ \\
\hline WPS1831 & $\begin{array}{l}\text { How Trade Patterns and Technology } \\
\text { Flows Affect Productivity Growth }\end{array}$ & Wolfgang Keller & September 1997 & $\begin{array}{l}\text { J. Ngaine } \\
37947\end{array}$ \\
\hline WPS1832 & $\begin{array}{l}\text { Pension Reform in Bolivia: Innovative } \\
\text { Solutions to Common Problems }\end{array}$ & Hermann von Gersdorff & September 1997 & $\begin{array}{l}\text { C. Paviak } \\
82099\end{array}$ \\
\hline WPS1833 & $\begin{array}{l}\text { Cost Recovery and Pricing of } \\
\text { Payment Services }\end{array}$ & $\begin{array}{l}\text { David B. Humphrey } \\
\text { Robert H. Keppler } \\
\text { Fernando Montes-Negret }\end{array}$ & October 1997 & $\begin{array}{l}\text { T. Ishibe } \\
38968\end{array}$ \\
\hline WPS1834 & $\begin{array}{l}\text { The Comparative Advantage of } \\
\text { Government: A Review }\end{array}$ & Pedro Belli & October 1997 & $\begin{array}{l}\text { L. Schunk } \\
31779\end{array}$ \\
\hline WPS1835 & $\begin{array}{l}\text { Cost-Benefit Analysis of the Global } \\
\text { Dracunculiasis Eradication Campaign }\end{array}$ & $\begin{array}{l}\text { Aehyung Kim } \\
\text { Ajay Tandon } \\
\text { Ernesto Ruiz-Tiben }\end{array}$ & October 1997 & $\begin{array}{l}\text { A. Kim } \\
35029\end{array}$ \\
\hline WPS1836 & $\begin{array}{l}\text { Health and Labor Productivity: The } \\
\text { Economic Impact of Onchocercal } \\
\text { Skin Disease }\end{array}$ & $\begin{array}{l}\text { Aehyung Kim } \\
\text { Ajay Tandon } \\
\text { Asrat Hairu and Others }\end{array}$ & October 1997 & $\begin{array}{l}\text { A. Kim } \\
35029\end{array}$ \\
\hline WPS1837 & $\begin{array}{l}\text { How Estonia's Economic Transition } \\
\text { Affected Employment and Wages } \\
\text { (1989-95) }\end{array}$ & $\begin{array}{l}\text { Rivo Noorkoiv } \\
\text { Peter F. Orazem } \\
\text { Allan Puur } \\
\text { Milan Vodopivec }\end{array}$ & October 1997 & $\begin{array}{l}\text { S. Fallon } \\
38009\end{array}$ \\
\hline WPS1838 & The Limits and Merits of Participation & $\begin{array}{l}\text { Paulo Vieira da Cunha } \\
\text { Maria Valeria Junho Pena }\end{array}$ & October 1997 & $\begin{array}{l}\text { E. Thomas } \\
31019\end{array}$ \\
\hline WPS1839 & $\begin{array}{l}\text { The Effects of Financial Liberalization } \\
\text { and New Bank Entry on Market } \\
\text { Structure and Competition in Turkey }\end{array}$ & Cevdet Denizer & November 1997 & $\begin{array}{l}\text { E. Khine } \\
37471\end{array}$ \\
\hline WPS1840 & Efficient Public Sector Downsizing & Martin Rama & November 1997 & $\begin{array}{l}\text { S. Fallon } \\
38009\end{array}$ \\
\hline WPS1841 & $\begin{array}{l}\text { Patterns of Metropolitan } \\
\text { Development: What Have We Learneo }\end{array}$ & $\begin{array}{l}\text { Gregory K. Ingram } \\
\text { d? }\end{array}$ & November 1997 & $\begin{array}{l}\text { J. Ponchamni } \\
31052\end{array}$ \\
\hline
\end{tabular}




\section{Policy Research Working Paper Series}

\section{Title}

WPS1842 Motorization and the Provision of Roads in Countries and Cities

WPS1843 Externalities and Bailouts: Hard and Soft Budget Constraints in Intergovernmental Fiscal Relations

WPS1844 Child Labor and Schooling in Ghana

WPS1845 Employment, Labor Markets, and Poverty in Ghana: A Study of Changes during Economic Decline and Recovery

WPS1846 Africa's Role in Multilateral Trade Negotiations

WPS1847 Outsiders and Regional Trade Agreements among Small Countries: The Case of Regional Markets

WPS1848 Regional Integration and Commodity Valeria De Bonis Tax Harmonization

WPS1849 Regional Integration and Factor Income Taxation

WPS1850 Determinants of Intra-Industry Trade between East and West Europe

WPS1851 Transportation Infrastructure Investments and Regional Trade Liberalization

WPS1852 Leading Indicators of Currency Crises

WPS1853 Pension Reform and Private Pension Monika Queisser Funds in Peru and Colombia

WPS1854 Regulatory Tradeoffs in Designing Concession Contracts for infrastructure Networks

WPS1855 Stabilization, Adjustment, and Growth Prospects in Transition Economies
Zhen Kun Wang

L. Alan Winters

Graciela Kaminsky

Saul Lizondo

Carmen M. Reinhart

November 1997

Anju Gupta

Maurice Schiff

Valeria De Bonis

Chonira Aturupane Simeon Djankov Bernard Hoekman

Eric W. Bond

November 1997

Claude Crampes

Antonio Estache

Cevdet Denizer
Date

November 1997

November 1997

J. Ngaine 37947

November 1997

S. Lizondo 85431

Contact

for paper

j. Ponchamni 31052

C. Bernardo 37699

B. Casely-Hayford 34672

B. Casely-Hayford 34672

J. Ngaine 37947

J. Ngaine 37947

J. Ngaine 37947

J. Ngaine 37947

J. Ngaine 37947

P. Infante 37642

November 1997

A. Estache 81442

November 1997

E. Khine 37471 